\title{
A Developed Data Envelopment Analysis Model for Efficient Sustainable Supply Chain Network Design
}

\author{
Zohreh Moghaddas $^{1}\left(\mathbb{D}\right.$, Babak Mohamadpour Tosarkani $^{2, *}$ and Samuel Yousefi $^{2}(\mathbb{D}$ \\ 1 Department of Mathematics and Statistics, Islamic Azad University, Qazvin Branch, \\ Qazvin P.O. Box 34185-1416, Iran; zmoghaddas@qiau.ac.ir \\ 2 School of Engineering, University of British Columbia, Okanagan Campus, Kelowna, BC V1V 1V7, Canada; \\ samuel.yousefi@ubc.ca \\ * Correspondence: babak.tosarkani@ubc.ca
}

check for updates

Citation: Moghaddas, Z.; Tosarkani, B.M.; Yousefi, S. A Developed Data Envelopment Analysis Model for Efficient Sustainable Supply Chain Network Design. Sustainability 2022, 14, 262. https://doi.org/10.3390/ su14010262

Academic Editor: Ming-Lang Tseng

Received: 1 November 2021

Accepted: 27 December 2021

Published: 27 December 2021

Publisher's Note: MDPI stays neutral with regard to jurisdictional claims in published maps and institutional affiliations.

Copyright: (C) 2021 by the authors. Licensee MDPI, Basel, Switzerland. This article is an open access article distributed under the terms and conditions of the Creative Commons Attribution (CC BY) license (https:// creativecommons.org/licenses/by/ $4.0 /)$.

\begin{abstract}
In recent years, various organizations have focused on considering the sustainability concept in the supply chain (SC) design. Managers try to increase the sustainability of SCs to achieve a competitive advantage in today's growing market. Designing a sustainable supply chain (SSC) by integrating economic, social, and environmental dimensions affects the SC's overall performance. To achieve the SSC, decision makers (DMs) are required to evaluate different strategies and then apply the most effective one to design SC networks. This study proposes an assessment approach based on the network data envelopment analysis (DEA) to choose an efficient strategy for each stage of an SSC network. This approach seeks to provide a sustainable design with DMs to avoid imposing additional costs on SCs that result from noncompliance with environmental and social issues. To this end, we consider sustainability-concept-related inputs and outputs in the network DEA model to choose the most efficient strategy for SSC design. The strategy selection process can become an important issue, especially when SCs active in a competitive environment. Accordingly, a crucial feature of the presented model is considering the issue of competition to choose the efficient strategy. Furthermore, undesirable outputs and feedbacks and independent inputs and outputs for intermediate stages in the network system are considered to create a structure compatible with the real world. The output of the proposed approach enables DMs to select the appropriate strategy for each stage of the SSC network to maximize the aggregate efficiency of the network.
\end{abstract}

Keywords: sustainable supply chain; strategy selection; network design; data envelopment analysis; aggregate efficiency

\section{Introduction}

Today, due to globalization, demand uncertainty, and economic competition, organizations are looking for the implementation of supply chain management (SCM) effectively to survive [1,2]. On the other hand, the concept of sustainability has been received more attention in recent years due to increasing socio-environmental problems, including climate change and air pollution [3,4]. Organizations, therefore, try to apply green practices in their supply chain (SC)-related operations to improve their social and environmental performances [5-7]. In fact, organizations seek to achieve a competitive position in today's market by simultaneously focusing on increasing internal efficiency and integrating the sustainability concept into SC operations [8-10]. In this regard, sustainable supply chain management (SSCM) is considered as the integration of traditional SC and green practices to improve environmental, social, and economic performance [11,12]. SSCM aims to manage the flow of materials, information, and capital in addition to cooperation between stakeholders throughout the SC. SSCM sets sustainability-based goals based on the needs of the customers and stakeholders [11]. Thus, the effective implementation of this type of management requires applying the economic, social, and environmental aspects in 
making sustainable decisions about the SC design $[13,14]$. The impact of each decision and design-related strategy can be investigated by evaluating the performance of the designed sustainable supply chain (SSC). Performance evaluation for effective SSCM and designing an efficient network is of cardinal importance [15].

To evaluate the performance or efficiency of SCs, decision makers (DMs) can use various approaches. In the meantime, the data envelopment analysis (DEA) is a mathematical modeling-based technique for calculating the relative efficiency of a set of decision-making units (DMUs) used in addressing the problems related to SCM [16,17]. DEA is a nonparametric method that uses multiple inputs to produce multiple outputs for determining the relative efficiencies within a group of DMUs $[1,18,19]$. As stated, one of the important aspects of SCM is evaluating the performance and efficiency scores of each member and the entire network. Focusing on the recent applications of DEA models in SSCM, Yu and Su [20] developed a fuzzy DEA model to address the green supplier selection problem by considering SC carbon footprints as an input of the model. He and Zhang [21] presented a novel hybrid approach based on factor analysis, DEA, and AHP, to solve the supplier selection problem under the respective low-carbon SC. Su and Sun [22] developed a network DEA model to consider the undesired outputs and dual-role factors to calculate the efficiency of DMUs with multiple stages. Additionally, Badiezadeh et al. [23] proposed a network DEA model for calculating optimistic and pessimistic efficiency to rank SSCs considering undesirable outputs. Zarbakhshnia and Jaghdani [24] introduced a novel two-stage DEA network model considering uncontrollable inputs and undesirable outputs and the set of intermediate elements between stages to evaluate the sustainable suppliers. In another study, Izadikhah and Saen [25] proposed a novel stochastic two-stage DEA model in the presence of undesirable data to evaluate the sustainability of SCs. Kalantary and Saen [26] developed a network dynamic DEA model and its inverse model to assess the sustainability of SCs in multiple periods. Zhou et al. [27] introduced a novel dynamic network DEA model with desirable and undesirable indicators based on the interval type-2 fuzzy sets to calculate the detailed efficiencies based on effective and invalid production frontiers in SSCs.

Krmac and Djordjević [28] used a nonradial DEA model for evaluating different components of SSCM. This model assesses the environmental efficiency of suppliers considering undesirable inputs and outputs. Lin et al. [29] proposed an inverse DEA model to evaluate the container ports' efficiency and analyze their resource consumption according to undesirable outputs. Tavassoli et al. [30] introduced four types of supplier selection models and proposed a stochastic-fuzzy DEA model to evaluate supplier's sustainability. Pachar et al. [31] presented a performance measurement approach based on a two-stage network DEA model to assess the impact of sustainable operations and operational activities on the retail industry performance. Dobos and Vörösmarty [32] used a common weights DEA model to determine a set of capable suppliers by considering the management and green criteria in the evaluation process. Vaez-Ghasemi et al. [33] used a DEA model, in which the weight restrictions on criteria are incorporated for cost efficiency evaluation in SSCs with marginal surcharge values for environmental factors. Shadab et al. [34] used the network DEA models by considering the role of intermediate products to measure the congestion in SSCs. Tavassoli et al. [35] developed a double frontier fuzzy DEA model for evaluating the optimistic and pessimistic sustainability of SCs of tomato paste. Rajak et al. [36] proposed an integrated DEA enhanced Russell measure model to evaluate the performance of transportation systems to minimize sustainability-related costs (e.g., cost of energy consumption and $\mathrm{CO} 2$ emission). Jomthanachai et al. [37] introduced an alternative coherent DEA with a representation of the intramural structure for measuring the efficiency of an SSC. This model can avoid the intermediate measures among different nodes in the SC. Moghaddas et al. [38] developed a DEA model to consider the dependencies between the production of desirable and undesirable outputs and used this model to evaluate the SSC. Fathi and Saen [39] developed a double frontier network DEA model with a common set of weights and fuzzy data to determine the optimistic, pessimistic, and double 
frontier sustainability of SCs. Zhao et al. [15] presented a DEA model-based approach to measuring the coordination effect of SC systems in a supplier-manufacturer sustainable SC. Song et al. [40] used a fuzzy DEA model and a characteristic function to modify the Shapley value model to distribute cooperative profit fairly in reverse logistics.

In practical applications of DEA in network design, nondiscretionary inputs, undesirable outputs, and negative outputs have been considered in the previous studies. Nevertheless, the issue of feedback has not been addressed as much as the mentioned issues in a network. Feedback is an output of one of the network stages that returned to previous stages as input. Notably, the outputs are either desirable or undesirable. The desirable feedbacks are outputs of a stage that are used as desirable inputs for previous stages for reducing costs, and undesirable feedbacks are the defective output of a stage. These outputs are returned to previous stages as inputs to be repaired. In this case, wastes are undesirable feedbacks that returned to previous stages for disposal. As can be seen from the examples given, considering feedback can include a variety of modes and affect SC performance. The strategy selection helps managers and DMs address the SSC network design due to organizational limitations. By implementing each strategy, a different efficiency score results for that system. Therefore, the issue of strategy selection concerns maximizing the efficiency score, which is a significant issue for DMs. What has not been studied in the DEA literature for strategy selection is maximizing the aggregate efficiency of the network. That is among the possible strategies for each of the network stages, the selected strategies ultimately maximize the aggregate efficiency score of the network.

In this study, we address the issue of strategy selection for different stages of a network. The key feature of this study is that each stage of the network selects its appropriate strategy to maximize the cumulative performance of the entire network. It is an issue that has not been considered in the DEA literature of the selection method using mathematical modeling. To this end, we propose a network DEA-based approach to select efficient strategies to design an SSC network. This approach employs sustainability concept-related inputs and outputs to choose the most efficient strategy for SSC design in a competitive environment. Additionally, the proposed model considers undesirable outputs and feedbacks and independent inputs and outputs for intermediate stages in the network system to increase compatibility with the real world. To put it precisely, the developed network DEA model considers the feedback of intermediate product in a network, which is the optimal output of a stage and used as the desirable input of previous stages. Furthermore, this study designs an SSC network, in which each stage tries to maximize the aggregate efficiency of the network. In this regard, we define various strategies for SSC network design and evaluate the efficiency of each stage and aggregate efficiency of the network. The output of the proposed approach determines the effective strategies for SSC network design to improve the SC performance based on the sustainability concept. The contributions of this research can be summarized as follows:

- Proposing a DEA-based mixed-integer linear programming (MILP) model to design an SSC network to maximize the aggregate efficiency of the network;

- Measuring the stage efficiency scores and the aggregate efficiency of the SC network simultaneously;

- Considering sustainability-related inputs and outputs in the strategy selection process;

- Considering the undesirable outputs, intermediate products, and feedbacks for designing an SSC network.

The rest of this research is organized as follows: Section 2 introduces the proposed DEA model. In Section 3, the outputs of the implementation of the developed model in a case study are provided. Finally, the conclusion and future research directions are discussed in Section 4.

\section{Methodology and Proposed Model}

In this section, a DEA model is developed for evaluating the strategies of SSC network design. Focusing on problem definition, it is significant to set the stages for each SSC so 
that each stage and the entire SC perform efficiently. Therefore, choosing possible efficient scenarios among various competitive alternatives is of cardinal importance. In this regard, we sought to select the best scenario for each stage based on the efficiency score. The implementation of the best strategy in each stage in a competitive environment can affect the quality and quantity, financial and stability, and the general conditions of the SSC. In this study, a MILP model based on the DEA technique is introduced to select the best scenario for each of the stages in the SSC to maximize aggregate efficiency. Notably, a list of possible scenarios and the appropriate weight for each stage efficiency score should be defined and determined by managers and DMs. An outline of the developed model is drawn in Figure 1. Additionally, the parameters and variables used in mathematical modeling are introduced in Table 1.

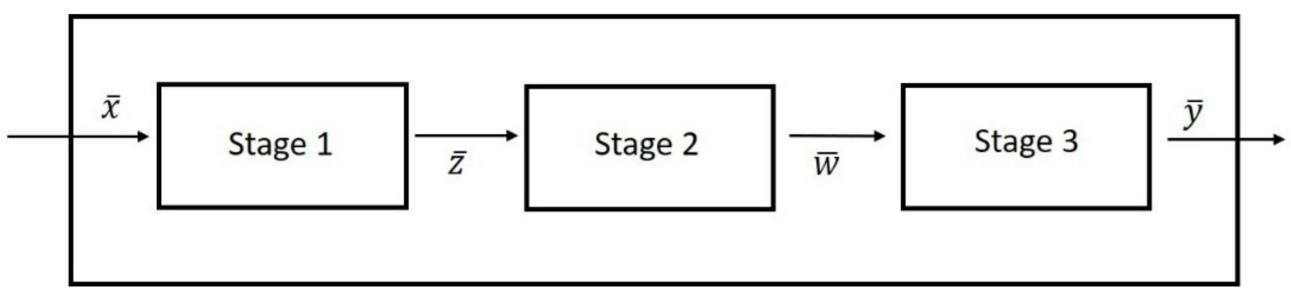

Figure 1. The SSC network based on DEA model.

Table 1. The indices, parameters, and variables used in developing the DEA model.

\begin{tabular}{|c|c|c|c|}
\hline \multicolumn{4}{|c|}{ Indices } \\
\hline$i$ & Index corresponds to $\bar{x}$ & $l$ & Index corresponds to $\bar{w}$ \\
\hline$g$ & Index corresponds to $\bar{z}$ & $j$ & Index corresponds to $D M U_{s}$ \\
\hline$r$ & Index corresponds to $y^{1}$ and $y^{2}$ & & \\
\hline \multicolumn{4}{|c|}{ Parameters } \\
\hline $\bar{x}_{i j}$ & The $i$ th input of stage 1 for $D M U_{j}$ & $\bar{z}_{g j}$ & $\begin{array}{l}\text { The } g \text { th output of stage } 1 \text { and input of stage } 2 \\
\text { (Intermediate product) for } D M U_{j}\end{array}$ \\
\hline $\bar{w}_{l j}$ & $\begin{array}{c}\text { The } l \text { th output of stage } 2 \text { and input of stage } 3 \text { (Intermediate } \\
\text { product) for } D M U_{j}\end{array}$ & $\bar{y}_{r j}$ & The $r$ th output of stage 3 for $D M U_{j}$ \\
\hline$x_{i j}$ & The $i$ th input of supplier for $D M U_{j}$ & $a_{d j}$ & The $d$ th output of supplier for $D M U_{j}$ \\
\hline$z_{g j}$ & $\begin{array}{l}\text { The gth output of supplier and input of manufacturer for } \\
\qquad D M U_{j}\end{array}$ & $d_{t j}$ & $\begin{array}{l}\text { The th input of manufacturer and output of } \\
\text { distributor for } D M U_{j}\end{array}$ \\
\hline$l_{k j}$ & The $k$ th input of manufacturer for $D M U_{j}$ & $w_{l j}$ & $\begin{array}{l}\text { The lth output of manufacturer and input of } \\
\text { distributor for } D M U_{j}\end{array}$ \\
\hline$p_{l j}$ & The $l$ th input of distributor for $D M U_{j}$ & $y_{r j}^{1}, y_{r j}^{2}$ & The $r$ th output of distributor for $D M U_{j}$ \\
\hline$q_{c j}$ & The $c$ th output of supplier for $D M U_{j}$ & $x_{i j}^{o}$ & The $i$ th input of supplier for $D M U_{o}$ \\
\hline$a_{d j}^{o}$ & The $d$ th output of supplier for $D M U_{o}$ & $z_{g j}^{o}$ & $\begin{array}{l}\text { The gth output of supplier and input of } \\
\text { manufacturer for } D M U_{0}\end{array}$ \\
\hline$d_{t j}^{o}$ & $\begin{array}{l}\text { The th input of manufacturer and output of distributor for } \\
\qquad D M U_{0}\end{array}$ & $l_{k j}^{o}$ & The $k$ th input of manufacturer for $D M U_{o}$ \\
\hline$w_{l j}^{o}$ & $\begin{array}{l}\text { The } l \text { th output of manufacturer and input of distributor for } \\
\qquad D M U_{o}\end{array}$ & $p_{l j}^{o}$ & The $l$ th input of distributor for $D M U_{o}$ \\
\hline$y_{r j}^{1 o}, y_{r j}^{2 o}$ & The $r$ th output of distributor for $D M U_{o}$ & $q_{c j}^{o}$ & The $c$ th output of supplier for $D M U_{O}$ \\
\hline$N$ & Number of $D M U s$ & $m$ & Number of elements for $\bar{X}$ \\
\hline$b$ & Number of elements for $\bar{Z}$ & $a$ & Number of elements for $\bar{W}$ \\
\hline$s$ & Number of elements for $\bar{Y}$ & $m_{1}$ & Number of elements for $x$ \\
\hline$m_{2}$ & Number of elements for $l$ & $m_{3}$ & Number of elements for $p$ \\
\hline$s_{1}$ & Number of elements for $y^{1}$ & $s_{2}$ & Number of elements for $y^{2}$ \\
\hline$s_{3}$ & Number of elements for $w$ & $s_{4}$ & Number of elements for $q$ \\
\hline$s_{5}$ & Number of elements for $a$ & $\bar{\omega}$ & Positive weights \\
\hline$M$ & A big positive scalar & $a$ & Number of elements for $w$ \\
\hline
\end{tabular}


Table 1. Cont.

\begin{tabular}{|c|c|c|c|}
\hline \multicolumn{4}{|c|}{ Variables } \\
\hline $\bar{v}_{i j}$ & The weight of $i$ th input of stage 1 for $D M U_{j}$ & $\bar{k}$ & $\begin{array}{c}\text { The weight of } g \text { th output of stage } 1 \text { and input of } \\
\text { stage } 2 \text { for } D M U_{j}\end{array}$ \\
\hline $\bar{f}_{l j}$ & $\begin{array}{l}\text { The weight of } l \text { th output of stage } 2 \text { and input of stage } 3 \text { for } \\
\qquad D M U_{j}\end{array}$ & $\bar{u}_{r j}$ & The weight of $r$ th output of stage 3 for $D M U_{j}$ \\
\hline$v_{i j}$ & The weight of $i$ th input of supplier for $D M U_{j}$ & $g_{d j}$ & The weight of $d$ th output of supplier for $D M U_{j}$ \\
\hline$k_{g j}$ & $\begin{array}{l}\text { The weight of } g \text { th output of supplier and input of } \\
\text { manufacturer for } D M U_{j}\end{array}$ & $e_{t j}$ & $\begin{array}{c}\text { The weight of } t \text { th input of manufacturer and } \\
\text { output of distributor for } D M U_{j}\end{array}$ \\
\hline$h_{k j}$ & The weight of $k$ th input of manufacturer for $D M U_{j}$ & $f_{l j}$ & $\begin{array}{l}\text { The weight of } l \text { th output of manufacturer and } \\
\text { input of distributor for } D M U_{j}\end{array}$ \\
\hline$c_{l j}$ & The weight of $l$ th input of distributor for $D M U_{j}$ & $u_{r j}^{1}$ & The weight of $r$ th output of distributor for $D M U_{j}$ \\
\hline$u_{r j}^{2}$ & The weight of $r$ th output of distributor for $D M U_{j}$ & $b_{c j}$ & The weight of $c$ th output of supplier for $D M U_{j}$ \\
\hline$t_{j}^{1}, t_{j}^{2}, t_{j}^{3}$ & Binary variables for each stage and $D M U_{j}$ & & \\
\hline
\end{tabular}

Based on Figure 1, an SSC is depicted with three stages connected in series. ' $\bar{x}$ ' is the independent input of the first stage. ' $\bar{z}$ ' is the intermediate product, which is the output of stage one and input of stage 2. ' $\bar{w}$ ' is the intermediate product between stage 2 and stage 3 . It is the output of stage 2 and the input of stage 3 . Finally, ' $\bar{y}$ ' is the output of stage 3 which is the final product of the SSC.

To develop a DEA model, we first developed Model (1). This model examines all possible strategies. Therefore, a strategy is selected to maximize the value of the objective function. In other words, by choosing that strategy, the efficiency of that stage is maximized. Model (1) was formulated to select the scenario for the first stage with the aim of maximizing its efficiency.

$$
\begin{array}{ll}
\operatorname{Max} \sum_{j=1}^{n}\left(\sum_{g=1}^{b} \bar{k}_{g j} \bar{z}_{g j}^{o}\left(1-t_{j}^{1}\right)\right) & \\
\text { s.t. } & \\
\sum_{i=1}^{m} \bar{v}_{i j} \bar{x}_{i j}=1, & j=1, \ldots, n, \\
\sum_{g=1}^{b} \bar{k}_{g j} \bar{z}_{g j}-\sum_{i=1}^{m} \bar{v}_{i j} \bar{x}_{i j} \leq M t_{j}^{1}, & \\
\sum_{j=1}^{n} t_{j}^{1}=n-1, & j=1, \ldots, n, \\
t_{j}^{1} \in\{0,1\}, & \\
\bar{k} \geq 1 \varepsilon, & \\
\bar{v} \geq 1 \varepsilon . &
\end{array}
$$

Constraint (1a) represents that the sum of weighted inputs for stage 1 for all DMUs is equal to 1 . The left side of constraint (1b) calculates the efficiency of the first stage of the network. In constraint (1c), the sum of variable $t_{j}^{1}$ over $j$ is considered equal to $n-1$. To address this inequality, big positive scalar $(M)$ is multiplied by the binary variable $t_{j}^{1}$ for all $j$ in the second constraint. According to the second and third constraints, the binary variable corresponding to $D M U_{j}$ is set to be equal to zero for the $D M U$ that has the highest efficiency in stage 1. In this way, the maximum value of stage 1 efficiency among all DMUs is determined, which is the optimal value of the objective function of Model (1). Constraints (1d) to (1f) represent the type of used variables.

Theorem 1. According to the optimal value of the objective function in Model (1), only one DMU with the highest efficiency score is selected for the first stage.

Proof of Theorem 1. As can be seen in Model (1), constraint (1c) assumes the sum of the variable $t_{j}^{1}(j=1, \ldots, n)$ to be equal to $n-1$. Therefore, out of a total of $n$ binary variables $t_{j}^{1}(j=1, \ldots, n, n-1$ binary variables have a value of 1 , and only one of them has a value of 0 . When $t_{j}^{1},(j=1, \ldots, n)$, takes a value of 1 , its corresponding constraint is redundant 
in constraint (1b). When $t_{j}^{1}(j=1, \ldots, n)$, takes a value of 0 , its corresponding constraint is established in constraint (1b), for example, for $j=p ; \sum_{g=1}^{b} \bar{k}_{g p} \bar{z}_{g p}-\sum_{i=1}^{m} \bar{v}_{i p} \bar{x}_{i p} \leq 0$. According to constraint (1a), the efficiency value of each $D M U_{j}(j=1, \ldots, n)$, is less than one, thus $\sum_{g=1}^{b} \bar{k}_{g j} \bar{z}_{g j} \leq 1(j=1, \ldots, n)$. Binary variables $t_{j}^{1}(j=1, \ldots, n)$ that have a value of 1 in the objective function reset their corresponding term to zero, leaving only one term in the objective function that has the maximum value of efficiency.

As shown in the following equations, Model (2) was formulated for selecting the strategy with the highest efficiency score for the second stage. According to the optimal value of the objective function in Model (2), only one DMU was selected for the second stage.

$$
\begin{array}{ll}
\operatorname{Max} \sum_{j=1}^{n}\left(\sum_{l=1}^{a} \bar{f}_{l j} \bar{w}_{l j}^{o}\left(1-t_{j}^{2}\right)\right) & \\
\text { s.t. } & j=1, \ldots, n, \\
\sum_{g=1}^{b} \bar{k}_{g j} \bar{z}_{g j}=1, & j=1, \ldots, n, \\
\sum_{l=1}^{a} \bar{f}_{l j} \bar{w}_{l j}-\sum_{g=1}^{b} \bar{k}_{g j} \bar{z}_{g j} \leq M t_{j}^{2}, & \\
\sum_{j=1}^{n} t_{j}^{2}=n-1, & \\
t_{j}^{2} \in\{0,1\}, & \\
\bar{k} \geq 1 \varepsilon, & \\
\bar{f} \geq 1 \varepsilon . &
\end{array}
$$

Constraints (2a) to (2f) can be explained similarly to constraints (1a) to (1f). The difference between these two models is focusing on two different stages. The maximum value of stage 2 efficiency among all DMUs is determined, which is the optimal value of the objective function of Model (2). Model (3) was formulated for selecting a strategy with the highest efficiency score for the third stage. Based on the optimal value of the objective function in Model (3), only one DMU was chosen for this stage.

$$
\begin{array}{ll}
\operatorname{Max} \sum_{j=1}^{n}\left(\sum_{l=1}^{s} \bar{u}_{r j} \bar{y}_{r j}^{o}\left(1-t_{j}^{3}\right)\right) & \\
\text { s.t. } & \\
\sum_{l=1}^{a} \bar{f}_{l j} \bar{w}_{l j}=1, & j=1, \ldots, n, \\
\sum_{r=1}^{s} \bar{u}_{r} \bar{y}_{r j}-\sum_{l=1}^{a} \bar{f}_{l j} \bar{w}_{l j} \leq M t_{j}^{3}, & j=1, \ldots, n, \\
\sum_{j=1}^{n} t_{j}^{3}=n-1, & j=1, \ldots, n, \\
t_{j}^{3} \in\{0,1\}, & \\
\bar{f} \geq 1 \varepsilon, & \\
\bar{u} \geq 1 \varepsilon . &
\end{array}
$$

Similar to previous models, constraints ( $3 a$ ) to (3f) can be discussed. However, this model seeks to determine the maximum value of stage 3 efficiency among all DMUs. The main aim of Models (1), (2), and (3) was to choose the best strategy from the existing ones for the network defined in Figure 1. The criterion for this selection is the efficiency score with the highest value. In these three models, the maximum efficiency of the first, second, and third stages was considered, respectively. Additionally, a binary variable and a big $M$ value were utilized, which empowered these models to choose the strategy with the maximum efficiency score.

The above-introduced models are MILP because the binary variable exists in the objective function and constraints. Thus, these models may have significant complexity due to having binary variables, so we attempted to introduce the linear equivalent of this model. The introduction of this linear model reduces the complexity of the nonlinear model and is one of the innovations of this modeling. The linear counterpart of Model (1) was formulated as Model (4). This model, similar to Model (1), seeks to select a strategy for the first stage with the highest efficiency score. 


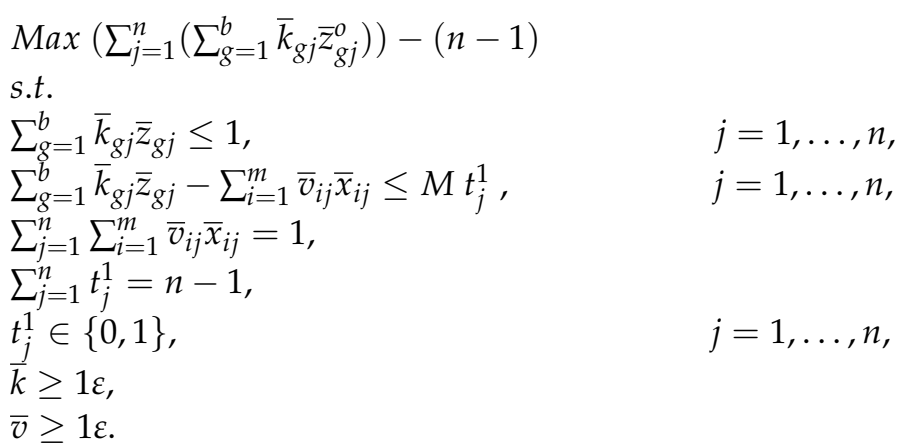

Constraint (4a) indicates the sum weighted outputs of stage 1 for all DMUs, which is set to be less than or equal to 1 . The left side of constraint $(4 \mathrm{~b})$ represents the efficiency of the first stage of the network. Constraint (4c) represents the sum weighted inputs of stage 1 for all DMUs is equal to 1 . Constraint (4d) guarantees the sum of variable $t_{j}^{1}$ over $j$ is equal to $n-1$. A big $M$ value is multiplied by the binary variable $t_{j}^{1}$ for all $j$ in the second constraint to address the created inequality. According to the second to fourth constraints, the binary variable corresponding to $D M U_{j}$ is set to be equal to zero for the $D M U$ that has the highest efficiency in stage 1 . In this way, the maximum value of stage 1 efficiency among all DMUs is determined, which is the optimal value of the objective function of Model (4). The rest of the constraints (4e to $4 \mathrm{~g}$ ) defines the type of used variables in developing this model.

Remark 1. The constraints (1a) and (1b) eliminate the nonlinear term in the objective function of Model (1). Due to the fourth constraint, not all of these binary variables can take a positive value, that is, a value of 1. According to this condition, one of the indices is established in constraint (1b), for example, for $j=p ; \sum_{g=1}^{b} \bar{k}_{g p} \bar{z}_{g p}-\sum_{i=1}^{m} \bar{v}_{i p} \bar{x}_{i p} \leq 0$. Then, the rest of constraint $(1 b)$ is redundant. it is worth noting that the goal of this model is to maximize the objective function. Therefore, with the help of binary variables $n-1$, inequalities in constraint (1b) are redundant. The efficiency score of $D M U_{j}$ corresponds to the redundant inequalities are bounded above by 1 in constraint (1a). The sum of these bounds is $n-1$, which is subtracted from the objective function. Thus, only one term in objective function remains, for instance, $\sum_{g=1}^{b} \bar{k}_{g p} \bar{z}_{g p}$ for which we have $t_{p}^{1}=0$. Therefore, in this model, there is no need for binary variables in the objective function.

The proposed MILP model was based on the principles of the CCR model and can find the most efficient scenario for the first stage of the chain. As shown in the following equations, the linear counterpart of Models (2) and (3) were formulated as Models (5) and (6), respectively. The main aim of Models (5) and (6) was to select a strategy with the highest efficiency score for the second and third stages independently. A similar note to Remark 1 was considered for these models. 


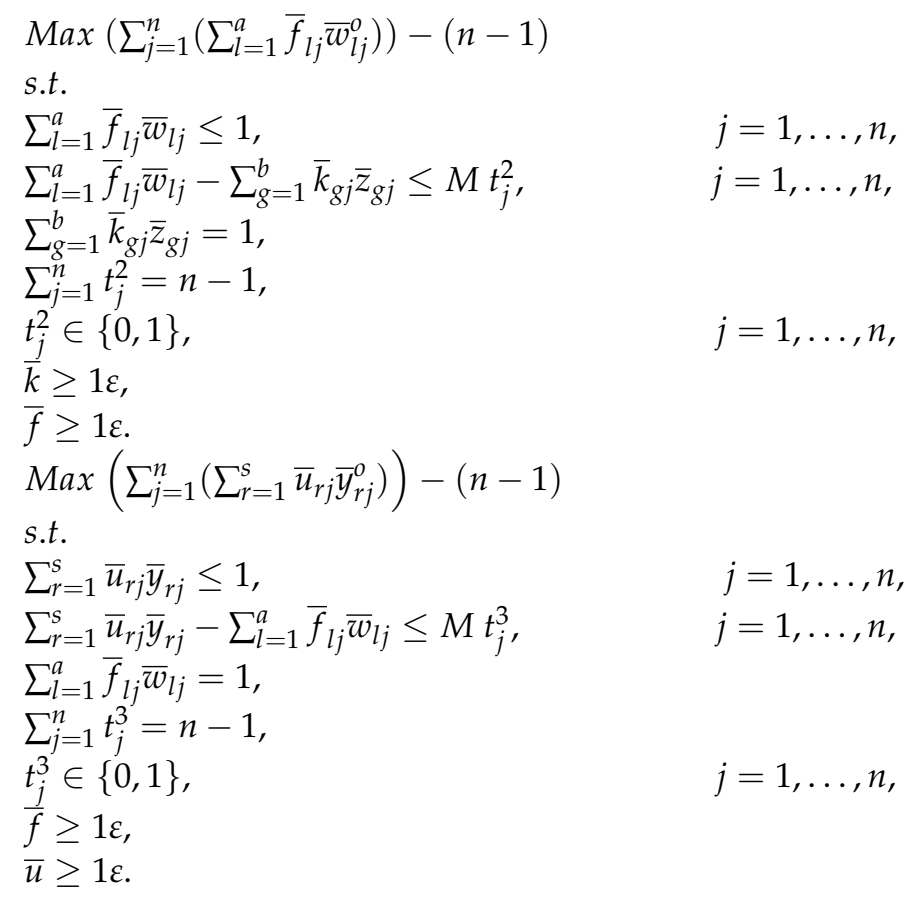

All constraints of the above-mentioned models, constraints (5a) to $(5 \mathrm{~g})$ and constraints (6a) to (6g), can be defined similarly to Model (4). The difference between these models is focusing on a specific stage of the network. Models (4) to (6) were developed for choosing the optimal strategy for each stage of an SSC. Now, if DMs want to choose three stages in an SSC network at the same time, the goal is to maximize the efficiency of the whole network. In fact, selecting all three strategies for all three stages affects the performance of the entire chain. Accordingly, we introduced the following model to measure aggregate efficiency. It should be noted that $\bar{\omega}_{1}, \bar{\omega}_{2}$, and $\bar{\omega}_{3}$ are weights that are set by DMs as a numerical coefficient for the performance of each stage. These weights show the importance of the efficiency values of each stage in the cumulative performance value of the whole network. The characteristic of these nonnegative numerical coefficients is that their sum must be one, i.e., $\bar{\omega}_{1}, \bar{\omega}_{2}, \bar{\omega}_{3} \geq 0, \bar{\omega}_{1}+\bar{\omega}_{2}+\bar{\omega}_{3}=1$. Model (7) was developed to select strategies with the highest aggregated efficiency for the first, second, and third stages of the SSC for $D M U_{0}$. 


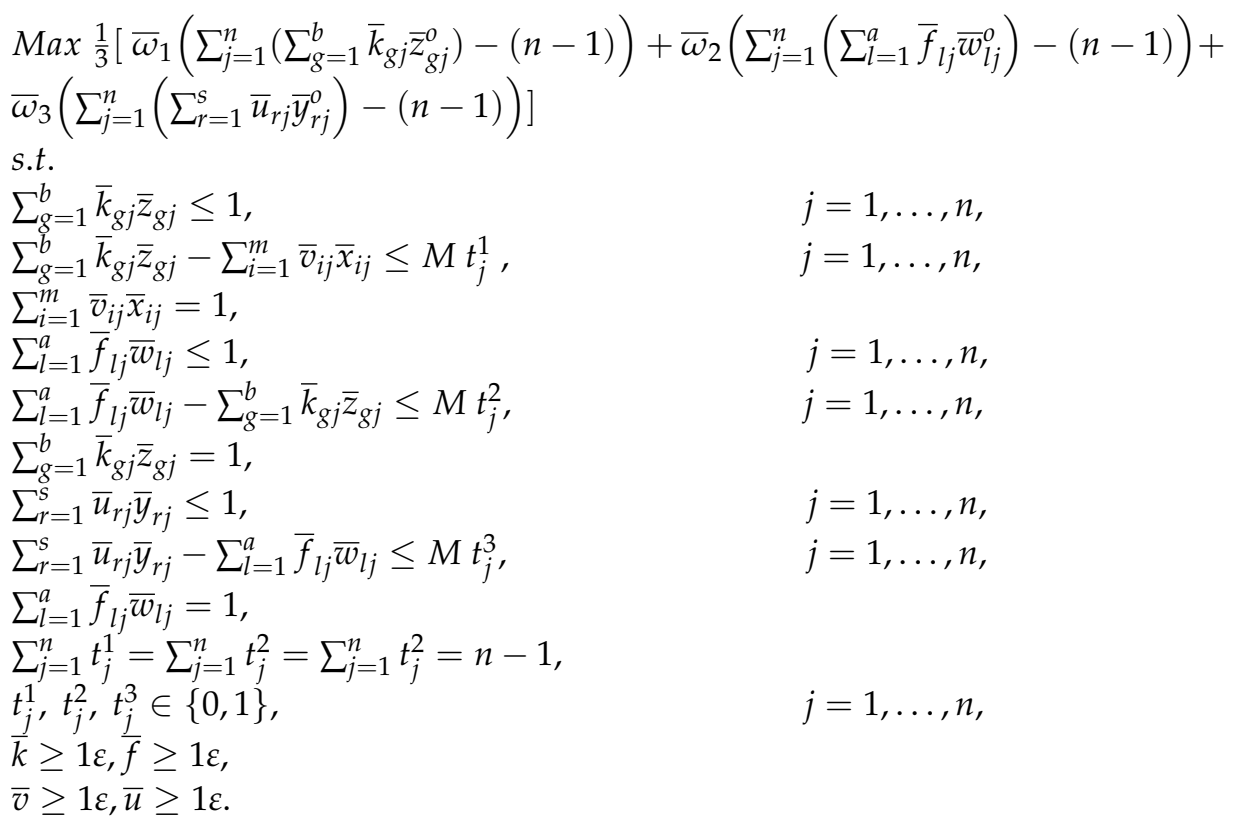

The objective function of Model (7) is the average of weighted efficiency scores of each stage of the studied network. Therefore, Model (7) seeks the maximum aggregate efficiency score of the entire network. Constraints $(7 \mathrm{a}),(7 \mathrm{~d})$, and $(7 \mathrm{~g})$ represent the sum weighted outputs of stages 1,2 , and 3 for all DMUs are set to be less than or equal to 1 . The sum weighted inputs of stages 1,2, and 3 for all DMUs are equal to 1 based on constraints (7c), (7f), and (7i). In constraint (7j), the sum of variables $t_{j}^{1}, t_{j}^{2}$, and $t_{j}^{3}$ over $j$ is considered equal to $n-1$. The left side of constraints (7b), (7e), and (7h) indicates the efficiency of stages 1,2 , and 3 in the network. To address the inequality of these constraints, a big $M$ value is multiplied by the binary variable $t_{j}^{1}, t_{j}^{2}$, and $t_{j}^{3}$ for all $j$. According to constraints (7a), (7b), and (7c), the binary variable corresponding to $D M U_{j}$ is set to be equal to zero for the $D M U$ that has the highest efficiency in stage 1. Similarly, based on (7d), (7e), and (7f), the binary variable associated with $D M U_{j}$ is set to be equal to zero for the $D M U$ that has the highest efficiency in stage 2 . According to $(7 \mathrm{~g}),(7 \mathrm{~h})$, and $(7 \mathrm{i})$, the binary variable corresponding to $D M U_{j}$ is set to be equal to zero for the $D M U$ that has the highest efficiency in stage 3. Constraints (7k) to $(7 \mathrm{~m})$ define the type of variables used in Model (7).

Remark 2. Consider the objective function of Model (7). $\bar{\omega}_{1}, \bar{\omega}_{2}$, and $\bar{\omega}_{3}$ are positive numeric weights introduced by DMs or managers to indicate the importance of each stage in calculating the aggregate efficiency of the entire network. As noted, the sum of the defined weights $\bar{\omega}_{1}, \bar{\omega}_{2}$, and $\bar{\omega}_{3}$ must be equal to 1 . Different choices of these weights may result in different outputs. For example, if in the calculating process of the aggregate efficiency of the entire chain, the supplier is more important than the manufacturer, and the manufacturer is more important than the distributor, the numbers $\frac{3}{6}, \frac{2}{6}$, and $\frac{1}{6}$ can be considered for the corresponding coefficients of stages 1,2 , and 3 . As evident in Model (7), the introduced objective function consists of three parts, each of which is the product of the factor multiplied by the expression of the efficiency of each stage. Notably, both of these numbers are less than one. Therefore, the sum of numbers after dividing by three is always less than or equal to 1. This value is the aggregate efficiency of the network. In other words, the objective function of Model (7) introduces the average of weighted efficiency scores of all stages as the aggregate efficiency of the network. The reason behind using $\frac{1}{3}$ in the objective function is that the aggregate efficiency score eventually becomes a value between zero and one.

Considering the network depicted in Figure 2 with three stages, $x$ indicates the input of the supplier with $m_{1}$ component. $q$ and $z$ are desirable outputs of this stage with $s_{4}$ and 
$b$ components, and $a$ is the undesirable output with $s_{5}$ components. The manufacturer uses $d, z$, and $l$ as its inputs, and produces $w$ as the output. $l, d$, and $w$ have $m_{2}, s_{3}$, and $t$ components, respectively. $p$ enters distributor as inputs with $m_{3}$ components, and $d$ leaves this stage as feedback to the manufacturer. Finally, $y$ is the output the of distributor that is the output of the system. Notably, Figure 2 shows a three echelon SC, including supplier, manufacturer, and distributor. Since SCM includes the processes of supplying the materials, producing the products, until delivering that product to the customer, the SC network can also have a fourth component called the retailer. According to the case study investigated in this research, the distributor and the retailer are considered as one component at the end of the chain. Therefore, modeling was performed based on a three echelon SC.

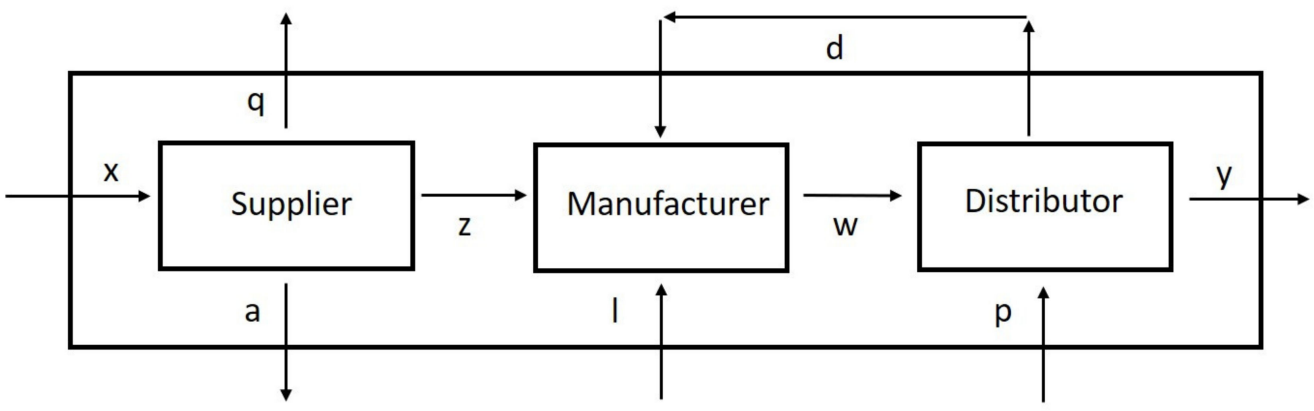

Figure 2. A general view of the studied SSC network.

As shown in the following, Model (8) was proposed to select the supplier with the highest efficiency score. It should be noted that $a$ is the undesirable output of the first stage, and the less amount of it is desired. Therefore, $a$ is considered as the input of the supplier. In Model (8), the second constraint examines all possible strategies. In the right of this constraint, there is a big $M$ value, which, along with the binary variable, helps to choose the optimal strategy. Binary variables are also present in the objective function, in addition to the values. Therefore, the strategy is selected to maximize the value of the corresponding objective function. In other words, the efficiency of the stage under investigation will be maximized by choosing that strategy.

$$
\begin{aligned}
& \operatorname{Max}\left(\sum_{j=1}^{n}\left(\sum_{g=1}^{b} k_{g j} z_{g j}^{o}+\sum_{c=1}^{r_{4}} b_{c j} q_{c j}^{o}\right)\right)-(n-1) \\
& \text { s.t. } \\
& \sum_{g=1}^{b} k_{g j} z_{g j}+\sum_{c=1}^{r_{4}} b_{c j} q_{c j} \leq 1, \\
& \sum_{g=1}^{b} k_{g j} z_{g j}+\sum_{c=1}^{r_{4}} b_{c j} q_{c j}- \\
& \sum_{i=1}^{m} v_{i j} x_{i j}-\sum_{d=1}^{r_{5}} g_{d j} a_{d j} \leq M t_{j}^{1}, \\
& \sum_{i=1}^{m} v_{i j} x_{i j}+\sum_{d=1}^{r_{5}} g_{d j} a_{d j}=1 \text {, } \\
& \sum_{j=1}^{n} t_{j}^{1}=n-1 \text {, } \\
& t_{j}^{1} \in\{0,1\} \text {, } \\
& k \geq 1 \varepsilon, b \geq 1 \varepsilon \text {, } \\
& v \geq 1 \varepsilon, g \geq 1 \varepsilon \text {. } \\
& j=1, \ldots, n, \\
& j=1, \ldots, n \text {, } \\
& j=1, \ldots, n,
\end{aligned}
$$

Constraint (8a) indicates the sum weighted desirable outputs of stage $1,{ }^{\prime \prime} z$ " and " $q$ ", for all $D M U$ s, which is set to be less than or equal to 1 . Constraint (8c) ensures that the sum weighted inputs of stage 1, " $x$ " and " $a$ ", for all DMUs is equal to 1 . An undesirable output of stage 1 is considered as an input. The sum of variable $t_{j}^{1}$ over $j$ is considered equal to $n-1$ in constraint (8d). The left side of constraint (8b) represents the efficiency of the first stage of the network. To address the existing inequality in this constraint, big $M$ is multiplied by the binary variable $t_{j}^{1}$ for all $j$. Based on constraints (8b) to (8d), the binary variable corresponding to $D M U_{j}$ is set to be equal to zero for the $D M U$ that has the highest efficiency in stage 1. In this way, the maximum value of the efficiency score of stage 1 among all DMUs is determined, which is the optimal value of the objective function 
of Model (8). Constraints (8e) to (8g) represent the type of used decision variables for developing this model.

Theorem 2. Using Model (8), only one strategy with the highest efficiency score is selected for the supplier.

Proof of Theorem 2. The binary variable $t_{j}^{1}$ is introduced in constraint (8e). This variable is used on the right side of constraint (8b). As the sum of $t_{j}^{1}$ is equal to $n-1$; thus, the $n-1$ binary variable takes a positive value, and the rest of them take a zero value. Thus, $n-1$ inequalities in constraint $(8 \mathrm{~b})$ are redundant. Let the second constraint for some $j=p$ hold; $\sum_{g=1}^{b} k_{g p} z_{g p}+\sum_{c=1}^{r_{4}} b_{c p} q_{c p}-\sum_{i=1}^{m} v_{i p} x_{i p}-\sum_{d=1}^{r_{5}} g_{d p} a_{d p} \leq 0$. It is concluded that these $n-1$ terms in the objective function are equal to 1 according to constraint (8a) that is bounded above by 1 . Therefore, the only term that remains in the objective function is $\sum_{g=1}^{b} k_{g p} z_{g p}+\sum_{c=1}^{r_{4}} b_{c p} q_{c p}$. It is worth noting that $\sum_{g=1}^{b} k_{g p} z_{g p}+\sum_{c=1}^{r_{4}} b_{c p} q_{c p}$ has the maximum value for objective function otherwise another $D M U_{j} j \neq p$ should remain in the objective function. As we know $\sum_{g=1}^{b} k_{g p} z_{g p}+\sum_{c=1}^{r_{4}} b_{c p} q_{c p}$ represents the relative efficiency score related to $D M U_{p}$ which is confined to be less than 1 .

Due to constraint (8d) presented in linear Model (8), not all of the binary variables can take a positive value, that is, a value of one. According to this condition, one of the indices is established in constraints (8b) and (8c) is redundant for the rest of the indices. Notably, the goal of Model (8) is to maximize the objective function, which is the efficiency score of the supplier. With the help of binary variables in constraints, a part remains in the objective function of this model that in constraint (8a) is bound to the values of less than 1 . Thus, in this model, there is no need for binary variables in the objective function. This MILP model is based on the principles of the CCR model and can find the most efficient scenario for each of the stages of the SSC network.

As shown in the following equations, Model (9) was formulated to select the manufacturer with the highest efficiency score. In this model, $d$ is the input of the manufacturer and the output of the distributor. In other words, $d$ is the feedback of the distributor to the manufacturer and can be desirable or undesirable. For example, we considered the output of the distributor as one of the raw materials required for the manufacturer. In this case, DMs can obtain $d$ from the distributor instead of buying $\mathrm{d}$ from outside the system to minimize the cost of the system. In another example, the product transported to the distributor, which was considered defective, can be referred to the manufacturer for inspection and troubleshooting. In this case, the output is undesirable, and its reduction is in favor of the system. In the mathematical modeling of the second and third stages, the output of the third stage, which goes back to the manufacturer, is considered a desirable factor. Finally, Model (10) was developed to select the distributor with the highest efficiency score. 


$$
\begin{aligned}
& \operatorname{Max}\left(\sum_{j=1}^{n}\left(\sum_{l=1}^{t} f_{l j} w_{l j}^{o}\right)\right)-(n-1) \\
& \text { s.t. } \\
& \sum_{l=1}^{t} f_{l j} w_{l j} \leq 1 \text {, } \\
& \sum_{l=1}^{t} f_{l j} w_{l j}-\sum_{g=1}^{b} k_{g j} z_{g j}- \\
& \sum_{k=1}^{m_{3}} h_{k j} l_{j} \sum_{j=1}^{n} \sum_{t=1}^{r_{3}} e_{t j} d_{t j} \leq M t_{j}^{2} \\
& \sum_{g=1}^{b} k_{g j} z_{g j}+\sum_{k=1}^{m_{3}} h_{k j} l_{j}+\sum_{t=1}^{r_{3}} e_{t j} d_{t j}=1 \text {, } \\
& \sum_{j=1}^{n} t_{j}^{2}=n-1 \text {, } \\
& t_{j}^{2} \in\{0,1\} \text {, } \\
& k \geq 1 \varepsilon, \geq 1 \varepsilon \text {, } \\
& f \geq 1 \varepsilon, d \geq 1 \varepsilon \text {. } \\
& j=1, \ldots, n, \\
& j=1, \ldots, n, \\
& j=1, \ldots, n,
\end{aligned}
$$

Constraints of Models (9) and (10) can be defined similarly to Model (8). Constraint (9a) represents the sum weighted outputs of stage 2, " $w$ ", for all DMUs is less than or equal to 1 . Constraint (9c) guarantees the sum weighted inputs of stage 2, " $z$ ", " $l$ ", and " $d$ ", for all $D M U$ s are equal to 1 . Notably, " $d$ " is the output of stage 3 that is returned to stage 2. Focusing on Model (10), constraint (10a) represents that the sum weighted outputs of stage 3 , " $d$ " and " $y$ ", for all DMUs is less than or equal to 1 . Constraint (10c) indicates that the sum weighted inputs of stage $3, " w$ ", " $y^{2}$ ", and " $p$ ", for all DMUs is equal to 1 similar to previous models. " $y$ " and " $y^{2}$ " is the undesirable and desirable outputs of stage 3 , respectively. The main aim of Models (8), (9), and (10) is to select the efficient strategy for SSC network design (see Figure 2). The efficient strategy is a strategy with the highest efficiency score. The mentioned three models sought the maximum efficiency of stages 1 to 3 , respectively. It can be said that the modification of the DEA model resulted in a linear model for efficiency evaluation, while the issue of selection was also considered. These models were formulated with the help of binary variables and introduced inequalities.

Lemma 1. Only one strategy with the highest efficiency score is selected for the manufacturer using Model (9).

Lemma 2. Based on Model (10), only one strategy with the highest efficiency score is selected for the distributor.

Models (8) to (10) were proposed for choosing the optimal strategy for each stage of an SSC. Now, to consider all three stages in an SSC at the same time, the efficiency of the whole network should be maximized. Since selecting all three strategies for all three stages affects the performance of the whole chain, we proposed Model (11) to address this issue. This network DEA model was formulated to select the supplier, manufacturer, and distributor in the SSC with the highest aggregated efficiency score. In this model, $\bar{\omega}_{1}, \bar{\omega}_{2}$, and $\bar{\omega}_{3}$ are weights that are set by the DMs to define different importance for the efficiency 
score of each stage in the aggregate efficiency score of the whole chain. The sum of these nonnegative numerical coefficients must be one, i.e., $\bar{\omega}_{1}, \bar{\omega}_{2}, \bar{\omega}_{3} \geq 0, \bar{\omega}_{1}+\bar{\omega}_{2}+\bar{\omega}_{3}=1$.

$$
\begin{aligned}
& \operatorname{Max} \frac{1}{3}\left[\bar{\omega}_{1}\left(\left(\sum_{j=1}^{n}\left(\sum_{g=1}^{b} k_{g j} z_{g j}^{o}+\sum_{c=1}^{s_{4}} b_{c j} q_{c j}^{o}\right)\right)-(n-1)\right)+\right. \\
& \bar{\omega}_{2}\left(\left(\sum_{j=1}^{n}\left(\sum_{l=1}^{t} f_{l j} w_{l j}^{o}\right)\right)-(n-1)\right)+ \\
& \left.\bar{\omega}_{3}\left(\left(\sum_{j=1}^{n}\left(\sum_{r=1}^{s_{1}} u_{r j}^{1} y_{r j}^{1 o}+\sum_{t=1}^{s_{3}} e_{t j} d_{t j}^{o}\right)\right)-(n-1)\right)\right] \\
& \text { s.t. } \\
& \sum_{g=1}^{b} k_{g j} z_{g j}+\sum_{c=1}^{s_{4}} b_{c j} q_{c j} \leq 1 \text {, } \\
& \sum_{g=1}^{b} k_{g j} z_{g j}+\sum_{c=1}^{s_{4}} b_{c j} q_{c j}-\sum_{i=1}^{m_{1}} v_{i j} x_{i j}- \\
& \sum_{d=1}^{S_{5}} g_{d j} a_{d j} \leq M t_{j}^{1} \\
& \sum_{i=1}^{m_{1}} v_{i j} x_{i j}+\sum_{d=1}^{s_{5}} g_{d j} a_{d j}=1 \text {, } \\
& \sum_{l=1}^{t} f_{l j} w_{l j} \leq 1 \text {, } \\
& \sum_{l=1}^{t} f_{l j} w_{l j}-\sum_{g=1}^{b} k_{g j} z_{g j}- \\
& \sum_{k=1}^{m_{2}} h_{k j} l_{j}-\sum_{t=1}^{r_{3}} e_{t j} d_{t j} \leq M t_{j}^{2} \text {, } \\
& \sum_{g=1}^{b} k_{g j} z_{g j}+\sum_{k=1}^{m_{2}} h_{k j} l_{j}+\sum_{t=1}^{s_{3}} e_{t j} d_{t j}=1 \text {, } \\
& \sum_{r=1}^{s_{1}} u_{r j}^{1} y_{r j}^{1}+\sum_{t=1}^{s_{3}} e_{t j} d_{t j} \leq 1 \text {, } \\
& \sum_{r=1}^{s} u_{r j}^{1} y_{r j}^{1}+\sum_{t=1}^{s_{3}} e_{t j} d_{t j}- \\
& \sum_{l=1}^{t} f_{l j} w_{l j}-\sum_{r=1}^{s_{2}} u_{r j}^{2} y_{r j}^{2}- \\
& \sum_{l=1}^{m_{3}} c_{l j} p_{l j} \leq M t_{j}^{3} \\
& \sum_{l=1}^{t} f_{l j} w_{l j}+\sum_{r=1}^{s_{2}} u_{r j}^{2} y_{r j}^{2}+ \\
& \sum_{l=1}^{m_{3}} c_{l j} p_{l j}=1 \text {, } \\
& \sum_{j=1}^{n} t_{j}^{1}=n-1, \sum_{j=1}^{n} t_{j}^{2}=n-1, \sum_{j=1}^{n} t_{j}^{3}=n-1 \\
& t_{j}^{1}, t_{j}^{2}, t_{j}^{3} \in\{0,1\} \text {, } \\
& j=1, \ldots, n, \\
& j=1, \ldots, n, \\
& j=1, \ldots, n, \\
& j=1, \ldots, n, \\
& j=1, \ldots, n, \\
& j=1, \ldots, n, \\
& v \geq 1 \varepsilon, f \geq 1 \varepsilon, k \geq 1 \varepsilon, \\
& h \geq 1 \varepsilon, \geq 1 \varepsilon, g \geq 1 \varepsilon \text {, } \\
& b \geq 1 \varepsilon, u^{1} \geq 1 \varepsilon, u^{2} \geq 1 \varepsilon, c \geq 1 \varepsilon \text {. }
\end{aligned}
$$

Model (11) searches for the maximum aggregate efficiency score of the entire network. Constraints (11a), (11d), and (11g) guarantee the sum weighted outputs of stages 1, 2, and 3 for all DMUs to be less than or equal to 1 . To ensure the sum weighted inputs of stages 1,2 , and 3 for all DMUs are equal to 1, we defined constraints (11c), (11f), and (11i). In constraint $(11 j)$, the sum of variables $t_{j}^{1}, t_{j}^{2}$, and $t_{j}^{3}$ over $j$ is considered equal to $n-1$. The left side of constraints (11b), (11e), and (11h) represents the efficiency of the first, second, and third stages of the network. In these constraints, a big $M$ value is multiplied by the binary variable $t_{j}^{1}, t_{j}^{2}$, and $t_{j}^{3}$ for all $j$. Based on constraints (11a) to (11i), the binary variable corresponding to $D M U_{j}$ is set to be equal to zero for the $D M U$ that has the highest efficiency in stags 1 to 3. Model (11) is an optimization model based on the DEA technique, considering the improvements applied to the classical DEA model. Model 11 as a network DEA model was developed for a three echelon SC. The improvement made in the classical DEA model is the consideration of all three stages in one model, which aims to select the best strategy for each stage in a way that maximizes the efficiency of the entire chain. Additionally, we considered undesirable outputs and returned outputs in the efficiency calculation process. It should be noted that the efficiency of the entire network is averaged over the weighted efficiency score of each stage. After solving Model (11), strategies were selected for each stage that maximized the aggregate efficiency of the network. In fact, this research used the efficiency score to address the problem of strategy selection to design SSCs.

Theorem 3. Using Model (11), strategies for the supplier, manufacturer, and distributor are selected with the aim of obtaining the highest aggregate efficiency score for the whole network. 
Proof of Theorem 3. According to Theorem 2 and Lemmas 1 and 2, strategies for each stage (supply, manufacturing, and distribution) are selected to maximize the aggregate efficiency score of the network.

\section{Application and Analysis of the Results}

In this section, the proposed DEA model is implemented in a practical case study to demonstrate its performance. To this end, this study aimed to assess 20 SSCs with similar structures active in the tomato paste production industry. For each SSC, three stages were considered in the studied network based on Figure 2. The list of 19 SSCs was derived from Tehran Stock Exchange and Iran Fara Bourse. In the first phase of the research methodology, an interview with experts was conducted to select the criteria for each stage of the studied network (Table 2). In the second phase, focusing on the sustainability concept, the values of the criteria, including inputs and outputs of the proposed model, were extracted from the Codal website. The values of the determined inputs and outputs for each stage are presented in Tables A1-A3. In the third phase, based on the case study definition, three strategies were assumed for each SSC based on the values of the inputs and outputs related to the supplier, manufacturer, and distributor. After defining strategies for 19 SSCs, the proposed model was used to select the best sustainable design strategy for each SSC in the fourth phase. The main aim of the implementation of Model (11) was to choose a specific design strategy for each SSC network to increase the aggregate sustainable efficiency of the entire network to the maximum possible level. Accordingly, the proposed network DEA model was introduced based on Models (8), (9), and (10) to consider three stages simultaneously to determine the efficient strategies for SSC design (Model 11). These strategies guarantee to maximize the efficiency of the whole chain. Notably, the efficiency of the whole chain was considered as the weighted average performance. In this study, $\bar{\omega}_{1}, \bar{\omega}_{2}$, and $\bar{\omega}_{3}$ were considered to be equal to $0.4,0.2$, and 0.4 based on DM's opinions.

Table 2. The inputs and outputs of the network DEA model.

\begin{tabular}{|c|c|c|c|}
\hline Factors & Notation & Definitions & Status \\
\hline \multirow{3}{*}{ Independent input of supplier } & $x_{1}$ & Raw materials & Desirable \\
\hline & $x_{2}$ & Staff (personnel) & Desirable \\
\hline & $x_{3}$ & Water usage & Desirable \\
\hline \multirow{2}{*}{ Output of supplier } & $q$ & $\mathrm{CO}_{2}$ emission & Undesirable \\
\hline & $a$ & Revenue & Desirable \\
\hline \multirow{2}{*}{$\begin{array}{l}\text { Output of supplier and input of } \\
\text { manufacturer (intermediate product) }\end{array}$} & $z_{1}$ & Inter-products & Desirable \\
\hline & $z_{2}$ & Supplied materials & Desirable \\
\hline Independent input of manufacturer & $L$ & Equipment costs & Desirable \\
\hline Input of manufacturer (feedback) & $D$ & Supplied materials & Desirable \\
\hline \multirow{2}{*}{$\begin{array}{l}\text { Output of manufacturer and input of } \\
\text { stage } 3 \text { (intermediate product) }\end{array}$} & $w_{1}$ & Products & Desirable \\
\hline & $w_{2}$ & Green products & Desirable \\
\hline Independent input of distributer & $P$ & Packaging costs & Desirable \\
\hline \multirow{3}{*}{ Output of distributer } & $y_{1}$ & Wastes & Undesirable \\
\hline & $y_{2}$ & Revenue & Desirable \\
\hline & $d_{1}$ & Supplied materials & Desirable \\
\hline
\end{tabular}

Next, the developed DEA (Model 11) was implemented according to the determined inputs and outputs to select the efficient strategy for SSC design. The results of the implementation of this model are presented in Table 3. According to the binary variables used in the developed models, one strategy was selected from all three strategies for designing each SSC network. This strategy selection process resulted in choosing 19 strategies with the highest aggregate efficiency values for their respective SSCs from the 57 existing strategies. 
Using $\mathrm{SSC}_{3}$ as an example, the calculated efficiency of supplier and manufacturer when we chose the first strategy was more than the second one. However, the second strategy was selected based on its highest aggregate efficiency resulting from the best performance of the distributor compared to the other two strategies. Among the studied SSC, the first strategy proposed for network design $\left(\mathrm{S}_{5,1}\right)$ had the greatest aggregate efficiency score considering the network members' efficiency in comparison with other ones. To put it precisely, if this strategy was used for designing $\mathrm{SSC}_{5}$, the designed network could outperform other SSCs in terms of factors related to the sustainability concept.

Table 3. The obtained efficiency scores for each strategy for the SSC network design.

\begin{tabular}{|c|c|c|c|c|c|c|}
\hline \multirow{2}{*}{$\begin{array}{l}\text { Sustainable } \\
\text { Supply Chain }\end{array}$} & \multirow{2}{*}{ Strategy } & \multicolumn{4}{|c|}{ Scores } & \multirow{2}{*}{ Selection } \\
\hline & & Supplier & Manufacturer & Distributor & Aggregate & \\
\hline \multirow{3}{*}{$\mathrm{SSC}_{1}$} & $S_{1,1}$ & 0.98 & 0.63 & 0.84 & 0.28 & 0 \\
\hline & $\mathrm{S}_{1,2}$ & $0.99^{*}$ & 0.71 & 0.79 & 0.29 & 1 \\
\hline & $\mathrm{S}_{1,3}$ & 0.9 & 0.6 & 0.93 & 0.28 & 0 \\
\hline \multirow{3}{*}{$\mathrm{SSC}_{2}$} & $\mathrm{~S}_{2,1}$ & 0.98 & 0.82 & 0.73 & 0.28 & 0 \\
\hline & $\mathrm{S}_{2,2}$ & 0.74 & 0.88 & 0.77 & 0.26 & 0 \\
\hline & $\mathrm{S}_{2,3}$ & 0.92 & 0.63 & 0.97 & 0.29 & 1 \\
\hline \multirow{3}{*}{$\mathrm{SSC}_{3}$} & $\mathrm{~S}_{3,1}$ & 1 & 1 & 0.66 & 0.29 & 0 \\
\hline & $\mathrm{S}_{3,2}$ & 0.91 & 0.72 & 0.98 & 0.3 & 1 \\
\hline & $S_{3,3}^{3,2}$ & 0.96 & 0.61 & 0.88 & 0.29 & 0 \\
\hline \multirow{3}{*}{$\mathrm{SSC}_{4}$} & $\mathrm{~S}_{4,1}$ & 1 & 0.68 & 0.75 & 0.28 & 0 \\
\hline & $\mathrm{S}_{4,2}$ & 0.92 & 0.67 & 1 & 0.3 & 1 \\
\hline & $S_{4,3}$ & 0.86 & 0.67 & 1 & 0.29 & 0 \\
\hline \multirow{3}{*}{$\mathrm{SSC}_{5}$} & $S_{5,1}$ & 0.95 & 0.79 & 1 & 0.31 & 1 \\
\hline & $\mathrm{S}_{5,2}$ & 0.95 & 0.81 & 0.69 & 0.27 & 0 \\
\hline & $\mathrm{S}_{5,3}$ & 0.91 & 0.72 & 0.95 & 0.3 & 0 \\
\hline \multirow{3}{*}{$\mathrm{SSC}_{6}$} & $S_{6,1}$ & 0.93 & 0.75 & 0.76 & 0.27 & 0 \\
\hline & $\mathrm{S}_{6,2}$ & 0.94 & 0.6 & 0.79 & 0.27 & 0 \\
\hline & $S_{6,3}$ & 0.92 & 0.7 & 0.96 & 0.3 & 1 \\
\hline \multirow{3}{*}{$\mathrm{SSC}_{7}$} & $S_{7,1}$ & 1 & 0.71 & 0.89 & 0.3 & 1 \\
\hline & $S_{7,2}$ & 0.95 & 0.6 & 0.82 & 0.28 & 0 \\
\hline & $\mathrm{S}_{7,3}$ & 1 & 0.9 & 0.67 & 0.28 & 0 \\
\hline \multirow{3}{*}{$\mathrm{SSC}_{8}$} & $S_{8,1}$ & 0.96 & 0.87 & 0.77 & 0.29 & 1 \\
\hline & $\mathrm{S}_{8,2}$ & 0.95 & 0.61 & 0.93 & 0.29 & 0 \\
\hline & $\mathrm{S}_{8,3}$ & 0.84 & 0.7 & 0.97 & 0.29 & 0 \\
\hline \multirow{3}{*}{$\mathrm{SSC}_{9}$} & $S_{9,1}$ & 0.93 & 0.75 & 0.76 & 0.27 & 0 \\
\hline & $\mathrm{S}_{9,2}$ & 1 & 0.63 & 0.88 & 0.29 & 0 \\
\hline & $S_{9,3}$ & 0.96 & 0.75 & 0.92 & 0.3 & 1 \\
\hline \multirow{3}{*}{$\mathrm{SSC}_{10}$} & $S_{10,1}$ & 0.94 & 0.74 & 0.83 & 0.29 & 1 \\
\hline & $S_{10,2}$ & 0.72 & 0.76 & 0.88 & 0.26 & 0 \\
\hline & $\mathrm{S}_{10,3}$ & 0.87 & 0.66 & 0.79 & 0.27 & 0 \\
\hline \multirow{3}{*}{$\mathrm{SSC}_{11}$} & $S_{11,1}$ & 0.74 & 0.85 & 0.86 & 0.27 & 0 \\
\hline & $S_{11,2}$ & 1 & 0.68 & 0.72 & 0.27 & 1 \\
\hline & $\mathrm{S}_{11,3}$ & 0.91 & 0.93 & 0.67 & 0.27 & 0 \\
\hline \multirow{3}{*}{$\mathrm{SSC}_{12}$} & $\mathrm{~S}_{12,1}$ & 1 & 0.82 & 0.7 & 0.28 & 0 \\
\hline & $S_{12,2}$ & 0.73 & 0.76 & 0.92 & 0.27 & 0 \\
\hline & $\mathrm{S}_{12,3}$ & 0.92 & 0.69 & 0.92 & 0.29 & 1 \\
\hline \multirow{3}{*}{$\mathrm{SSC}_{13}$} & $\mathrm{~S}_{13,1}$ & 0.76 & 0.83 & 0.91 & 0.28 & 0 \\
\hline & $\mathrm{S}_{13,2}$ & 1 & 0.8 & 0.76 & 0.29 & 0 \\
\hline & $S_{13,3}$ & 1 & 0.64 & 0.83 & 0.29 & 1 \\
\hline
\end{tabular}


Table 3. Cont.

\begin{tabular}{|c|c|c|c|c|c|c|}
\hline \multirow{2}{*}{$\begin{array}{l}\text { Sustainable } \\
\text { Supply Chain }\end{array}$} & \multirow{2}{*}{ Strategy } & \multicolumn{4}{|c|}{ Scores } & \multirow{2}{*}{ Selection } \\
\hline & & Supplier & Manufacturer & Distributor & Aggregate & \\
\hline \multirow{3}{*}{$\mathrm{SSC}_{14}$} & $S_{14,1}$ & 0.95 & 1 & 0.62 & 0.28 & 0 \\
\hline & $\mathrm{S}_{14,2}$ & 1 & 0.76 & 0.8 & 0.29 & 0 \\
\hline & $\mathrm{S}_{14,3}$ & 0.91 & 0.62 & 1 & 0.3 & 1 \\
\hline \multirow{3}{*}{$\mathrm{SSC}_{15}$} & $S_{15,1}$ & 1 & 0.7 & 1 & 0.31 & 1 \\
\hline & $S_{15,2}^{1,1}$ & 1 & 0.71 & 0.93 & 0.3 & 0 \\
\hline & $\mathrm{S}_{15,3}$ & 0.81 & 0.83 & 0.72 & 0.26 & 0 \\
\hline \multirow{3}{*}{$\mathrm{SSC}_{16}$} & $S_{16,1}$ & 0.84 & 0.76 & 0.78 & 0.27 & 0 \\
\hline & $S_{16,2}$ & 0.95 & 0.6 & 0.97 & 0.3 & 1 \\
\hline & $S_{16,3}$ & 1 & 0.83 & 0.69 & 0.28 & 0 \\
\hline \multirow{3}{*}{$\mathrm{SSC}_{17}$} & $S_{17,1}$ & 0.94 & 0.74 & 0.81 & 0.28 & 0 \\
\hline & $S_{17,2}$ & 0.98 & 0.62 & 1 & 0.31 & 1 \\
\hline & $\mathrm{S}_{17,3}$ & 1 & 0.77 & 0.8 & 0.29 & 0 \\
\hline \multirow{3}{*}{$\mathrm{SSC}_{18}$} & $S_{18,1}$ & 0.83 & 0.71 & 0.89 & 0.28 & 0 \\
\hline & $S_{18,2}$ & 1 & 0.62 & 0.8 & 0.28 & 1 \\
\hline & $S_{18,3}$ & 0.77 & 0.71 & 0.88 & 0.27 & 0 \\
\hline \multirow{3}{*}{$\mathrm{SSC}_{19}$} & $S_{19,1}$ & 0.98 & 0.86 & 0.79 & 0.29 & 0 \\
\hline & $\mathrm{S}_{19,2}$ & 0.95 & 0.6 & 0.84 & 0.28 & 0 \\
\hline & $\mathrm{S}_{19,3}$ & 0.97 & 0.7 & 0.98 & 0.31 & 1 \\
\hline
\end{tabular}

* The bold values indicate the selected strategy for each SSC design.

Figure 3 illustrates the efficiency scores obtained for each stage with respect to the selected strategy for deigning each SSC. Based on this figure, suppliers in $\mathrm{SSC}_{7}, \mathrm{SSC}_{11}$, $\mathrm{SSC}_{15}$, and $\mathrm{SSC}_{18}$ had the maximum efficiency score (the value of 1 ). Regarding the manufacturers active in the studied SSCs, the manufacture of $\mathrm{SSC}_{8}$ with an efficiency score of 0.87 outperformed other manufactures. As shown in Figure 3, for most SCs, the efficiency of the manufacturer was lower than the efficiency scores of supplier and distributor. Notably, the values of efficiency scores obtained for the supplier and distributor were approximately equal in the studied SSCs. Distributers of $\mathrm{SSC}_{4}, \mathrm{SSC}_{5}, \mathrm{SSC}_{14}, \mathrm{SSC}_{15}$, and $\mathrm{SSC}_{18}$ showed the highest possible efficiency score in comparison with other ones.

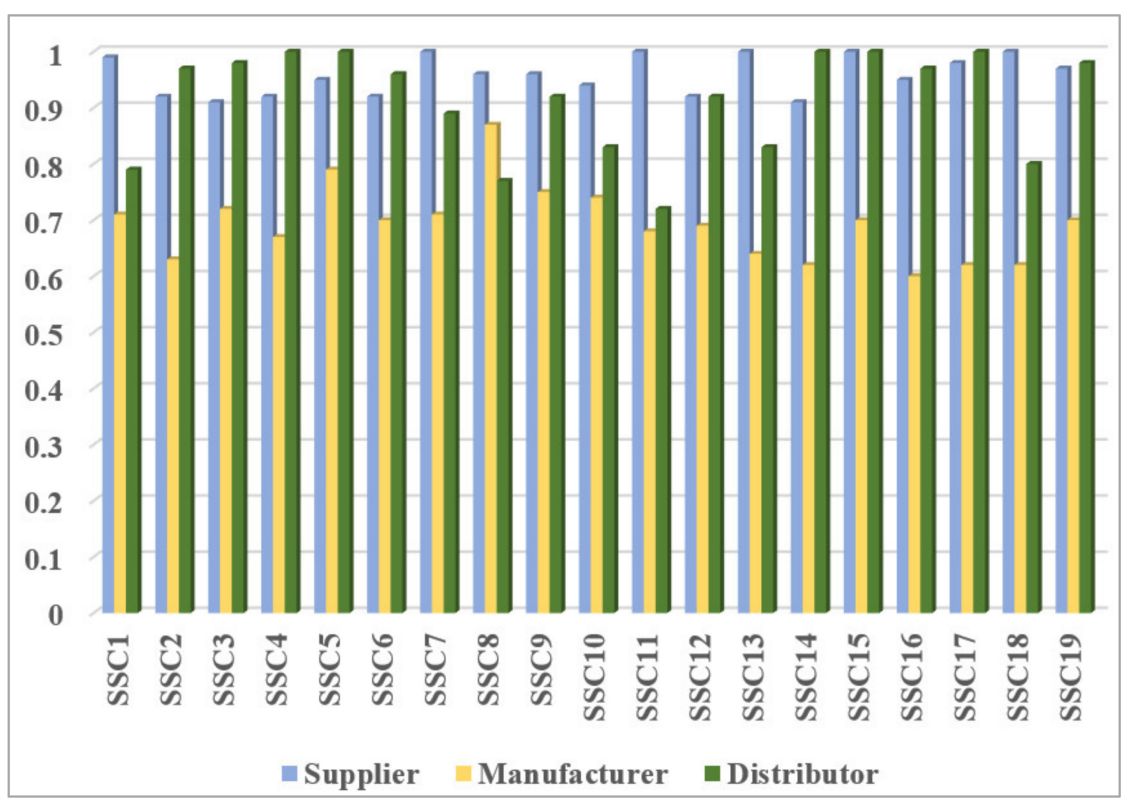

Figure 3. Efficiency scores of the supplier, manufacturer, and distributor. 
Based on Figure 4, it can be seen that four SSCs had an aggregate efficiency score more than the average score after performing their respective best strategies. Conversely, 17 SSCs showed the aggregate efficiency equal to the average value. However, these SSCs should follow the strategies proposed to design SSCs with an efficiency more than average to achieve maximum sustainability.

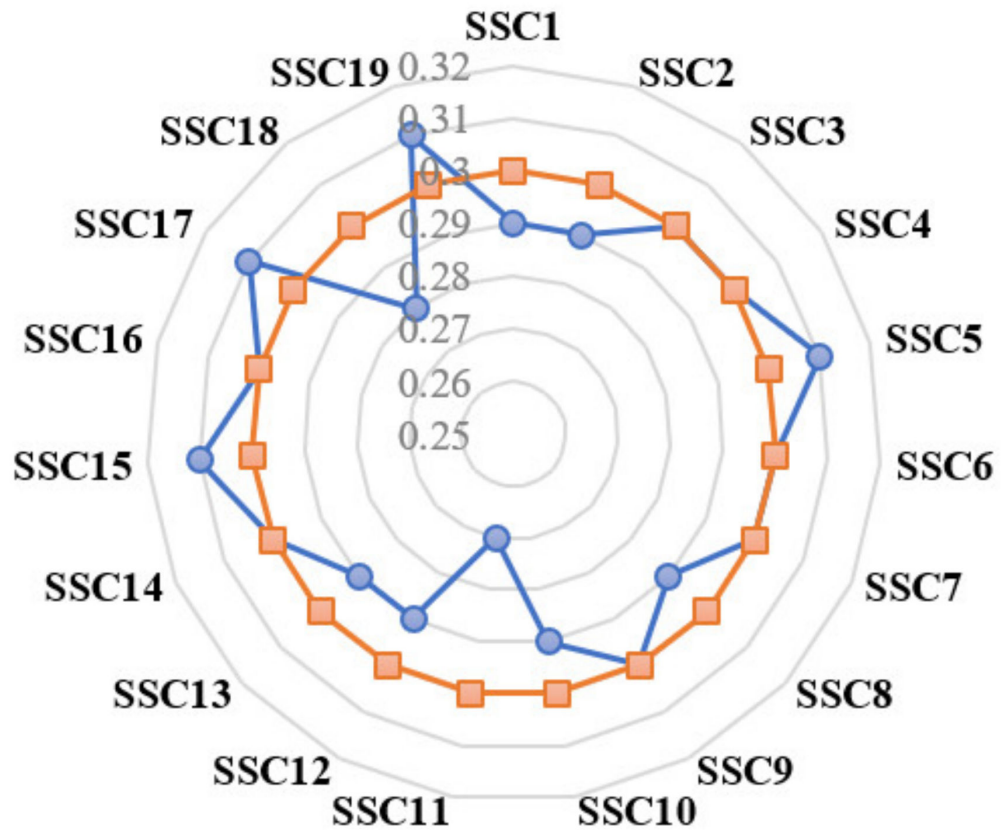

Aggregate Efficiency Score

Average Efficience Score

Figure 4. The comparison of the aggregate efficiency scores with respect to the average level.

SSCM seeks to balance economic, environmental, and social performance in SC networks. Achieving an SSC by simultaneously considering these three aspects can provide a competitive position in today's market. In fact, a significant problem in this market is the competition between companies for obtaining the best performance. In this competitive environment, to reach the best performance, reducing risks in network design is one of the key factors DMs and managers should particularly consider. A crucial feature of the model presented in this study is that it considers the issue of competition to choose the best strategy. Another one is to reduce the risk in the selection, and the introduced model considers the maximum aggregate efficiency of the chain.

\section{Conclusions}

In this era, the goal of organizations and companies is to increase profits, as well as survive in the existing competitive market. In fact, the rapid growth of technology and limited resources has put companies in close competition. One of the competitive advantages for companies is to make their supply chain activities more efficient. On the other hand, due to government laws, environmental issues, and the expansion of social responsibility, SSC design by integrating environmental considerations in the traditional SC networks has become more important. Accordingly, this study proposed a novel network DEA model for selecting the best sustainable strategy for SC network design. An advantage of the model is that it considers both efficiency of each stage as well as the aggregate efficiency of the entire network. In fact, the developed model was used to select the best strategy with the highest aggregate efficiency among different strategies in an SSC network considering the sustainability-related factors. Furthermore, the best strategy was chosen for each stage of the studied networks with the maximum efficiency, compared with other possible ones. 
To consider a network structure suitable for real-world applications, undesirable output, feedbacks, independent inputs for intermediate stages, and independent outputs of intermediate stages in the network were considered in this model. The outputs of this study can provide a decision-making system for managers and DMs to select the efficient strategies to design an SSC. This system aimed to maximize the aggregate efficiency of the network after implementing an SSC design strategy. Developing the proposed model by considering the concept of shared resources can be a future development suggestion to cover more applications in real-world problems. Furthermore, weight restrictions or leader-follower methods can be considered in the proposed models to apply importance between stages.

Author Contributions: Conceptualization, Z.M. and B.M.T.; methodology, Z.M.; software, Z.M.; formal analysis, Z.M. and S.Y.; writing-original draft preparation, Z.M. and S.Y.; writing-review and editing, B.M.T. and S.Y.; supervision, B.M.T. All authors have read and agreed to the published version of the manuscript.

Funding: This research received no external funding.

Institutional Review Board Statement: Not applicable.

Informed Consent Statement: Not applicable.

Data Availability Statement: The data used in this study can be obtained by contacting the corresponding author.

Conflicts of Interest: The authors declare no conflict of interest.

\section{Appendix A}

Table A1. The values of the inputs and outputs related to the supplier.

\begin{tabular}{|c|c|c|c|c|c|c|c|c|}
\hline \multirow{2}{*}{$\begin{array}{l}\text { Sustainable } \\
\text { Supply Chain }\end{array}$} & \multirow{2}{*}{ Strategy } & \multicolumn{3}{|c|}{ Input } & \multicolumn{4}{|c|}{ Output } \\
\hline & & $x_{1}$ & $x_{2}$ & $x_{3}$ & $q$ & $a$ & $z_{1}$ & $z_{2}$ \\
\hline \multirow{3}{*}{$\mathrm{SSC}_{1}$} & $\mathrm{~S}_{1,1}$ & 630 & 57 & 34,000 & 191 & 500 & 320 & 2500 \\
\hline & $\mathrm{S}_{1,2}$ & 450 & 90 & 20,000 & 160 & 530 & 290 & 1700 \\
\hline & $\mathrm{S}_{1,3}$ & 540 & 70 & 34,000 & 152 & 454 & 310 & 3000 \\
\hline \multirow{3}{*}{$\mathrm{SSC}_{2}$} & $\mathrm{~S}_{2,1}$ & 630 & 57 & 24,000 & 191 & 500 & 290 & 2800 \\
\hline & $\mathrm{S}_{2,2}$ & 450 & 80 & 30,000 & 152 & 400 & 210 & 1700 \\
\hline & $\mathrm{S}_{2,3}$ & 540 & 70 & 32,000 & 160 & 415 & 290 & 2500 \\
\hline \multirow{3}{*}{$\mathrm{SSC}_{3}$} & $\mathrm{~S}_{3,1}$ & 630 & 57 & 20,000 & 191 & 500 & 300 & 1700 \\
\hline & $\mathrm{S}_{3,2}$ & 630 & 70 & 30,000 & 152 & 415 & 290 & 2500 \\
\hline & $\mathrm{S}_{3,3}$ & 450 & 70 & 24,000 & 191 & 534 & 210 & 2800 \\
\hline \multirow{3}{*}{$\mathrm{SSC}_{4}$} & $\mathrm{~S}_{4,1}$ & 540 & 80 & 24,000 & 160 & 415 & 320 & 3000 \\
\hline & $\mathrm{S}_{4,2}$ & 500 & 90 & 40,000 & 200 & 467 & 310 & 3000 \\
\hline & $\mathrm{S}_{4,3}$ & 630 & 57 & 34,000 & 152 & 500 & 210 & 2500 \\
\hline \multirow{3}{*}{$\mathrm{SSC}_{5}$} & $\mathrm{~S}_{5,1}$ & 500 & 90 & 30,000 & 160 & 400 & 290 & 1700 \\
\hline & $\mathrm{S}_{5,2}$ & 450 & 70 & 24,000 & 160 & 415 & 300 & 2800 \\
\hline & $\mathrm{S}_{5,3}$ & 540 & 90 & 24,000 & 200 & 521 & 290 & 2500 \\
\hline \multirow{3}{*}{$\mathrm{SSC}_{6}$} & $S_{6,1}$ & 500 & 90 & 30,000 & 160 & 400 & 290 & 1700 \\
\hline & $S_{6,2}$ & 450 & 70 & 24,000 & 152 & 415 & 300 & 3000 \\
\hline & $\mathrm{S}_{6,3}$ & 540 & 90 & 24,000 & 200 & 521 & 290 & 2500 \\
\hline \multirow{3}{*}{$\mathrm{SSC}_{7}$} & $\mathrm{~S}_{7,1}$ & 500 & 90 & 30,000 & 200 & 400 & 290 & 2800 \\
\hline & $\mathrm{S}_{7,2}$ & 450 & 70 & 24,000 & 160 & 415 & 300 & 3000 \\
\hline & $\mathrm{S}_{7,3}$ & 540 & 57 & 24,000 & 200 & 521 & 320 & 2500 \\
\hline
\end{tabular}


Table A1. Cont.

\begin{tabular}{|c|c|c|c|c|c|c|c|c|}
\hline \multirow{2}{*}{$\begin{array}{l}\text { Sustainable } \\
\text { Supply Chain }\end{array}$} & \multirow{2}{*}{ Strategy } & \multicolumn{3}{|c|}{ Input } & \multicolumn{4}{|c|}{ Output } \\
\hline & & $x_{1}$ & $x_{2}$ & $x_{3}$ & $q$ & $a$ & $z_{1}$ & $z_{2}$ \\
\hline \multirow{3}{*}{$\mathrm{SSC}_{8}$} & $\mathrm{~S}_{8,1}$ & 500 & 90 & 30,000 & 160 & 400 & 290 & 2800 \\
\hline & $\mathrm{S}_{8,2}$ & 450 & 70 & 24,000 & 160 & 415 & 300 & 2800 \\
\hline & $\mathrm{S}_{8,3}$ & 540 & 90 & 32,000 & 200 & 521 & 310 & 2500 \\
\hline \multirow{3}{*}{$\mathrm{SSC}_{9}$} & $\mathrm{~S}_{9,1}$ & 500 & 90 & 30,000 & 160 & 400 & 290 & 2800 \\
\hline & $\mathrm{S}_{9,2}$ & 450 & 70 & 24,000 & 200 & 415 & 300 & 2800 \\
\hline & $\mathrm{S}_{9,3}$ & 540 & 90 & 24,000 & 200 & 521 & 320 & 2500 \\
\hline \multirow{3}{*}{$\mathrm{SSC}_{10}$} & $\mathrm{~S}_{10,1}$ & 500 & 90 & 30,000 & 152 & 400 & 290 & 1700 \\
\hline & $\mathrm{S}_{10,2}$ & 450 & 70 & 24,000 & 152 & 415 & 210 & 3000 \\
\hline & $\mathrm{S}_{10,3}$ & 540 & 90 & 34,000 & 200 & 521 & 320 & 2800 \\
\hline \multirow{3}{*}{$\mathrm{SSC}_{11}$} & $\mathrm{~S}_{11,1}$ & 500 & 90 & 30,000 & 160 & 400 & 210 & 1700 \\
\hline & $\mathrm{S}_{11,2}$ & 450 & 70 & 24,000 & 160 & 415 & 320 & 3000 \\
\hline & $\mathrm{S}_{11,3}$ & 540 & 90 & 24,000 & 200 & 521 & 290 & 2500 \\
\hline \multirow{3}{*}{$\mathrm{SSC}_{12}$} & $\mathrm{~S}_{12,1}$ & 500 & 90 & 30000 & 160 & 400 & 310 & 1700 \\
\hline & $\mathrm{S}_{12,2}$ & 450 & 80 & 24,000 & 160 & 415 & 210 & 3000 \\
\hline & $\mathrm{S}_{12,3}$ & 540 & 90 & 24,000 & 200 & 521 & 320 & 2500 \\
\hline \multirow{3}{*}{$\mathrm{SSC}_{13}$} & $\mathrm{~S}_{13,1}$ & 500 & 90 & 30,000 & 160 & 400 & 210 & 1700 \\
\hline & $\mathrm{S}_{13,2}$ & 450 & 57 & 24,000 & 160 & 454 & 310 & 2800 \\
\hline & $\mathrm{S}_{13,3}$ & 540 & 57 & 34,000 & 152 & 530 & 320 & 2500 \\
\hline \multirow{3}{*}{$\mathrm{SSC}_{14}$} & $S_{14,1}$ & 500 & 90 & 2,0000 & 160 & 467 & 290 & 1700 \\
\hline & $\mathrm{S}_{14,2}$ & 500 & 57 & 24,000 & 160 & 415 & 300 & 3000 \\
\hline & $\mathrm{S}_{14,3}$ & 540 & 90 & 24,000 & 200 & 521 & 290 & 2500 \\
\hline \multirow{3}{*}{$\mathrm{SSC}_{15}$} & $\mathrm{~S}_{15,1}$ & 500 & 57 & 34,000 & 160 & 400 & 290 & 2800 \\
\hline & $\mathrm{S}_{15,2}$ & 450 & 70 & 2,0000 & 152 & 415 & 300 & 3000 \\
\hline & $\mathrm{S}_{15,3}$ & 540 & 90 & 24,000 & 152 & 521 & 290 & 2500 \\
\hline \multirow{3}{*}{$\mathrm{SSC}_{16}$} & $S_{16,1}$ & 500 & 90 & 3,0000 & 160 & 454 & 290 & 2800 \\
\hline & $S_{16,2}$ & 450 & 80 & 32,000 & 160 & 467 & 300 & 3000 \\
\hline & $\mathrm{S}_{16,3}$ & 540 & 90 & 2,0000 & 200 & 521 & 290 & 2800 \\
\hline \multirow{3}{*}{$\mathrm{SSC}_{17}$} & $S_{17,1}$ & 500 & 57 & 3,0000 & 160 & 454 & 290 & 1700 \\
\hline & $S_{17,2}$ & 450 & 70 & 24,000 & 191 & 530 & 300 & 3000 \\
\hline & $\mathrm{S}_{17,3}$ & 540 & 90 & 2,0000 & 200 & 521 & 290 & 2500 \\
\hline \multirow{3}{*}{$\mathrm{SSC}_{18}$} & $S_{18,1}$ & 500 & 90 & 3,0000 & 160 & 467 & 290 & 2800 \\
\hline & $\mathrm{S}_{18,2}$ & 450 & 57 & 24,000 & 152 & 415 & 300 & 3000 \\
\hline & $\mathrm{S}_{18,3}$ & 540 & 80 & 34,000 & 152 & 500 & 290 & 2800 \\
\hline \multirow{3}{*}{$\mathrm{SSC}_{19}$} & $\mathrm{~S}_{19,1}$ & 500 & 90 & 3,0000 & 191 & 400 & 290 & 1700 \\
\hline & $S_{19,2}$ & 450 & 70 & 24,000 & 160 & 415 & 300 & 3000 \\
\hline & $\mathrm{S}_{19,3}$ & 540 & 90 & 24,000 & 200 & 467 & 310 & 2500 \\
\hline
\end{tabular}


Table A2. The values of the inputs and outputs related to the manufacturer.

\begin{tabular}{|c|c|c|c|c|c|c|c|}
\hline \multirow{2}{*}{$\begin{array}{l}\text { Sustainable } \\
\text { Supply Chain }\end{array}$} & \multirow{2}{*}{ Strategy } & \multicolumn{4}{|c|}{ Input } & \multicolumn{2}{|c|}{ Output } \\
\hline & & $z_{1}$ & $z_{2}$ & 1 & $d$ & $w_{1}$ & $w_{2}$ \\
\hline \multirow{3}{*}{$\mathrm{SSC}_{1}$} & $S_{1,1}$ & 320 & 2500 & 1200 & 80 & 4000 & 600 \\
\hline & $\mathrm{S}_{1,2}$ & 290 & 1700 & 2000 & 70 & 3500 & 450 \\
\hline & $\mathrm{S}_{1,3}$ & 310 & 3000 & 3200 & 85 & 4000 & 400 \\
\hline \multirow{3}{*}{$\mathrm{SSC}_{2}$} & $\mathrm{~S}_{2,1}$ & 290 & 2800 & 1200 & 70 & 5200 & 450 \\
\hline & $\mathrm{S}_{2,2}$ & 210 & 1700 & 3500 & 60 & 5600 & 350 \\
\hline & $\mathrm{S}_{2,3}$ & 290 & 2500 & 2000 & 85 & 4000 & 400 \\
\hline \multirow{3}{*}{$\mathrm{SSC}_{3}$} & $S_{3,1}$ & 300 & 1700 & 1200 & 80 & 6300 & 600 \\
\hline & $\mathrm{S}_{3,2}$ & 290 & 2500 & 3200 & 85 & 5200 & 400 \\
\hline & $\mathrm{S}_{3,3}$ & 210 & 2800 & 2000 & 75 & 4000 & 350 \\
\hline \multirow{3}{*}{$\mathrm{SSC}_{4}$} & $\mathrm{~S}_{4,1}$ & 320 & 3000 & 1200 & 80 & 5200 & 400 \\
\hline & $\mathrm{S}_{4,2}$ & 310 & 3000 & 3200 & 85 & 5000 & 400 \\
\hline & $\mathrm{S}_{4,3}$ & 210 & 2500 & 1200 & 70 & 5200 & 450 \\
\hline \multirow{3}{*}{$\mathrm{SSC}_{5}$} & $\mathrm{~S}_{5,1}$ & 290 & 1700 & 1200 & 80 & 6300 & 350 \\
\hline & $\mathrm{S}_{5,2}$ & 300 & 2800 & 3500 & 70 & 4000 & 600 \\
\hline & $\mathrm{S}_{5,3}$ & 290 & 2500 & 3200 & 85 & 5200 & 400 \\
\hline \multirow{3}{*}{$\mathrm{SSC}_{6}$} & $S_{6,1}$ & 290 & 1700 & 1200 & 80 & 6300 & 350 \\
\hline & $S_{6,2}$ & 300 & 3000 & 2000 & 70 & 4000 & 350 \\
\hline & $\mathrm{S}_{6,3}$ & 290 & 2500 & 3200 & 85 & 5200 & 400 \\
\hline \multirow{3}{*}{$\mathrm{SSC}_{7}$} & $S_{7,1}$ & 290 & 2800 & 1200 & 80 & 6300 & 350 \\
\hline & $S_{7,2}$ & 300 & 3000 & 2000 & 70 & 4000 & 350 \\
\hline & $S_{7,3}$ & 320 & 2500 & 3200 & 85 & 5200 & 600 \\
\hline \multirow{3}{*}{$\mathrm{SSC}_{8}$} & $\mathrm{~S}_{8,1}$ & 290 & 2800 & 1200 & 80 & 6300 & 500 \\
\hline & $\mathrm{S}_{8,2}$ & 300 & 2800 & 3500 & 70 & 4000 & 350 \\
\hline & $\mathrm{S}_{8,3}$ & 310 & 2500 & 3200 & 85 & 5200 & 400 \\
\hline \multirow{3}{*}{$\mathrm{SSC}_{9}$} & $\mathrm{~S}_{9,1}$ & 290 & 2800 & 1200 & 80 & 6300 & 350 \\
\hline & $\mathrm{S}_{9,2}$ & 300 & 2800 & 3500 & 70 & 4000 & 350 \\
\hline & $\mathrm{S}_{9,3}$ & 320 & 2500 & 3200 & 85 & 5200 & 500 \\
\hline \multirow{3}{*}{$\mathrm{SSC}_{10}$} & $S_{10,1}$ & $290>$ & $1700>$ & 1200 & 80 & 6300 & 350 \\
\hline & $S_{10,2}$ & 210 & 3000 & 2000 & 70 & 4000 & 350 \\
\hline & $S_{10,3}$ & 320 & 2800 & 3200 & 85 & 5200 & 400 \\
\hline \multirow{3}{*}{$\mathrm{SSC}_{11}$} & $S_{11,1}$ & 210 & 1700 & 1200 & 80 & 6300 & 350 \\
\hline & $S_{11,2}$ & 320 & 3000 & 3500 & 70 & 4000 & 500 \\
\hline & $\mathrm{S}_{11,3}$ & 290 & 2500 & 3200 & 85 & 5200 & 600 \\
\hline \multirow{3}{*}{$\mathrm{SSC}_{12}$} & $\mathrm{~S}_{12,1}$ & 310 & 1700 & 1200 & 80 & 6300 & 500 \\
\hline & $\mathrm{S}_{12,2}$ & 210 & 3000 & 2000 & 70 & 4000 & 350 \\
\hline & $\mathrm{S}_{12,3}$ & 320 & 2500 & 3200 & 85 & 5200 & 400 \\
\hline \multirow{3}{*}{$\mathrm{SSC}_{13}$} & $S_{13,1}$ & 210 & 1700 & 1200 & 80 & 6300 & 350 \\
\hline & $S_{13,2}$ & 310 & 2800 & 3500 & 70 & 4000 & 600 \\
\hline & $\mathrm{S}_{13,3}$ & 320 & 2500 & 3000 & 85 & 5200 & 400 \\
\hline \multirow{3}{*}{$\mathrm{SSC}_{14}$} & $S_{14,1}$ & 290 & 1700 & 1200 & 80 & 6300 & 600 \\
\hline & $S_{14,2}$ & 300 & 3000 & 2000 & 60 & 5600 & 350 \\
\hline & $\mathrm{S}_{14,3}$ & 290 & 2500 & 3000 & 85 & 4000 & 400 \\
\hline \multirow{3}{*}{$\mathrm{SSC}_{15}$} & $S_{15,1}$ & 290 & 2800 & 1200 & 80 & 6300 & 350 \\
\hline & $S_{15,2}$ & 300 & 3000 & 3000 & 70 & 5000 & 350 \\
\hline & $S_{15,3}$ & 290 & 2500 & 3200 & 60 & 5600 & 400 \\
\hline
\end{tabular}


Table A2. Cont.

\begin{tabular}{|c|c|c|c|c|c|c|c|}
\hline \multirow{2}{*}{$\begin{array}{l}\text { Sustainable } \\
\text { Supply Chain }\end{array}$} & \multirow{2}{*}{ Strategy } & \multicolumn{4}{|c|}{ Input } & \multicolumn{2}{|c|}{ Output } \\
\hline & & $z_{1}$ & $z_{2}$ & 1 & $d$ & $w_{1}$ & $w_{2}$ \\
\hline \multirow{3}{*}{$\mathrm{SSC}_{16}$} & $S_{16,1}$ & 290 & 2800 & 1200 & 80 & 6300 & 350 \\
\hline & $\mathrm{S}_{16,2}$ & 300 & 3000 & 3000 & 70 & 4000 & 350 \\
\hline & $\mathrm{S}_{16,3}$ & 290 & 2800 & 3200 & 60 & 5600 & 400 \\
\hline \multirow{3}{*}{$\mathrm{SSC}_{17}$} & $S_{17,1}$ & 290 & 1700 & 1200 & 70 & 5600 & 350 \\
\hline & $S_{17,2}$ & 300 & 3000 & 3500 & 70 & 4000 & 350 \\
\hline & $S_{17,3}$ & 290 & 2500 & 3000 & 70 & 5000 & 400 \\
\hline \multirow{3}{*}{$\mathrm{SSC}_{18}$} & $\mathrm{~S}_{18,1}$ & 290 & 2800 & 1200 & 80 & 6300 & 350 \\
\hline & $\mathrm{S}_{18,2}$ & 300 & 3000 & 2000 & 70 & 4000 & 350 \\
\hline & $\mathrm{S}_{18,3}$ & 290 & 2800 & 3200 & 85 & 3500 & 600 \\
\hline \multirow{3}{*}{$\mathrm{SSC}_{19}$} & $S_{19,1}$ & 290 & 1700 & 3000 & 85 & 6300 & 500 \\
\hline & $S_{19,2}$ & 300 & 3000 & 2000 & 70 & 4000 & 350 \\
\hline & $\mathrm{S}_{19,3}$ & 310 & 2500 & 3200 & 85 & 5200 & 400 \\
\hline
\end{tabular}

Table A3. The values of the inputs and outputs related to the distributor.

\begin{tabular}{|c|c|c|c|c|c|c|c|}
\hline \multirow{2}{*}{$\begin{array}{l}\text { Sustainable } \\
\text { Supply Chain }\end{array}$} & \multirow{2}{*}{ Strategy } & \multicolumn{4}{|c|}{ Input } & \multicolumn{2}{|c|}{ Output } \\
\hline & & $w_{1}$ & $w_{2}$ & $p$ & $d$ & $o_{1}$ & $o_{2}$ \\
\hline \multirow{3}{*}{$\mathrm{SSC}_{1}$} & $S_{1,1}$ & 4000 & 600 & 700 & 80 & 1800 & 4500 \\
\hline & $\mathrm{S}_{1,2}$ & 3500 & 450 & 900 & 70 & 2500 & 4700 \\
\hline & $\mathrm{S}_{1,3}$ & 4000 & 400 & 700 & 85 & 1500 & 5500 \\
\hline \multirow{3}{*}{$\mathrm{SSC}_{2}$} & $S_{2,1}$ & 5200 & 450 & 700 & 70 & 2000 & 4500 \\
\hline & $\mathrm{S}_{2,2}$ & 5600 & 350 & 800 & 60 & 1800 & 4700 \\
\hline & $\mathrm{S}_{2,3}$ & 4000 & 400 & 500 & 85 & 1500 & 5000 \\
\hline \multirow{3}{*}{$\mathrm{SSC}_{3}$} & $S_{3,1}$ & 6300 & 600 & 900 & 80 & 2500 & 5000 \\
\hline & $\mathrm{S}_{3,2}$ & 5200 & 400 & 440 & 85 & 1800 & 5500 \\
\hline & $S_{3,3}$ & 4000 & 350 & 581 & 75 & 1500 & 4500 \\
\hline \multirow{3}{*}{$\mathrm{SSC}_{4}$} & $\mathrm{~S}_{4,1}$ & 5200 & 400 & 900 & 80 & 2500 & 4700 \\
\hline & $\mathrm{S}_{4,2}$ & 5000 & 400 & 440 & 85 & 1800 & 5500 \\
\hline & $\mathrm{S}_{4,3}$ & 5200 & 450 & 328 & 70 & 2000 & 5000 \\
\hline \multirow{3}{*}{$\mathrm{SSC}_{5}$} & $S_{5,1}$ & 6300 & 350 & 253 & 80 & 2500 & 4700 \\
\hline & $\mathrm{S}_{5,2}$ & 4000 & 600 & 900 & 70 & 2000 & 4700 \\
\hline & $\mathrm{S}_{5,3}$ & 5200 & 400 & 500 & 85 & 1500 & 5500 \\
\hline \multirow{3}{*}{$\mathrm{SSC}_{6}$} & $S_{6,1}$ & 6300 & 350 & 900 & 80 & 1800 & 4700 \\
\hline & $S_{6,2}$ & 4000 & 350 & 900 & 70 & 2000 & 4700 \\
\hline & $S_{6,3}$ & 5200 & 400 & 440 & 85 & 2500 & 4500 \\
\hline \multirow{3}{*}{$\mathrm{SSC}_{7}$} & $S_{7,1}$ & 6300 & 350 & 700 & 80 & 1800 & 5500 \\
\hline & $S_{7,2}$ & 4000 & 350 & 800 & 70 & 2000 & 4700 \\
\hline & $S_{7,3}$ & 5200 & 600 & 900 & 85 & 1500 & 4500 \\
\hline \multirow{3}{*}{$\mathrm{SSC}_{8}$} & $\mathrm{~S}_{8,1}$ & 6300 & 500 & 440 & 80 & 2500 & 4700 \\
\hline & $\mathrm{S}_{8,2}$ & 4000 & 350 & 700 & 70 & 2000 & 5500 \\
\hline & $\mathrm{S}_{8,3}$ & 5200 & 400 & 415 & 85 & 1500 & 4500 \\
\hline \multirow{3}{*}{$\mathrm{SSC}_{9}$} & $S_{9,1}$ & 6300 & 350 & 900 & 80 & 1800 & 4700 \\
\hline & $S_{9,2}$ & 4000 & 350 & 700 & 70 & 2500 & 4700 \\
\hline & $\mathrm{S}_{9,3}$ & 5200 & 500 & 440 & 85 & 1500 & 5500 \\
\hline \multirow{3}{*}{$\mathrm{SSC}_{10}$} & $S_{10,1}$ & 6300 & 350 & 500 & 80 & 1800 & 4700 \\
\hline & $S_{10,2}$ & 4000 & 350 & 800 & 70 & 2000 & 4700 \\
\hline & $S_{10,3}$ & 5200 & 400 & 900 & 85 & 2500 & 4500 \\
\hline
\end{tabular}


Table A3. Cont.

\begin{tabular}{|c|c|c|c|c|c|c|c|}
\hline \multirow{2}{*}{$\begin{array}{l}\text { Sustainable } \\
\text { Supply Chain }\end{array}$} & \multirow{2}{*}{ Strategy } & \multicolumn{4}{|c|}{ Input } & \multicolumn{2}{|c|}{ Output } \\
\hline & & $w_{1}$ & $w_{2}$ & $p$ & $d$ & $o_{1}$ & $o_{2}$ \\
\hline \multirow{3}{*}{$\mathrm{SSC}_{11}$} & $S_{11,1}$ & 6300 & 350 & 700 & 80 & 1800 & 4700 \\
\hline & $\mathrm{S}_{11,2}$ & 4000 & 500 & 900 & 70 & 2000 & 4700 \\
\hline & $\mathrm{S}_{11,3}$ & 5200 & 600 & 900 & 85 & 1500 & 4500 \\
\hline \multirow{3}{*}{$\mathrm{SSC}_{12}$} & $\mathrm{~S}_{12,1}$ & 6300 & 500 & 800 & 80 & 2500 & 4700 \\
\hline & $\mathrm{S}_{12,2}$ & 4000 & 350 & 900 & 70 & 2000 & 5500 \\
\hline & $\mathrm{S}_{12,3}$ & 5200 & 400 & 500 & 85 & 1500 & 4500 \\
\hline \multirow{3}{*}{$\mathrm{SSC}_{13}$} & $\mathrm{~S}_{13,1}$ & 6300 & 350 & 440 & 80 & 1800 & 4700 \\
\hline & $\mathrm{S}_{13,2}$ & 4000 & 600 & 700 & 70 & 2500 & 5000 \\
\hline & $\mathrm{S}_{13,3}$ & 5200 & 400 & 415 & 85 & 1500 & 4500 \\
\hline \multirow{3}{*}{$\mathrm{SSC}_{14}$} & $\mathrm{~S}_{14,1}$ & 6300 & 600 & 800 & 80 & 1800 & 4700 \\
\hline & $\mathrm{S}_{14,2}$ & 5600 & 350 & 522 & 60 & 2000 & 4700 \\
\hline & $\mathrm{S}_{14,3}$ & 4000 & 400 & 500 & 85 & 2500 & 4500 \\
\hline \multirow{3}{*}{$\mathrm{SSC}_{15}$} & $\mathrm{~S}_{15,1}$ & 6300 & 350 & 440 & 60 & 1800 & 5500 \\
\hline & $\mathrm{S}_{15,2}$ & 5000 & 350 & 440 & 70 & 2000 & 5000 \\
\hline & $\mathrm{S}_{15,3}$ & 5600 & 400 & 500 & 85 & 1500 & 4500 \\
\hline \multirow{3}{*}{$\mathrm{SSC}_{16}$} & $S_{16,1}$ & 6300 & 350 & 900 & 85 & 2500 & 4700 \\
\hline & $\mathrm{S}_{16,2}$ & 4000 & 350 & 500 & 70 & 2000 & 5000 \\
\hline & $S_{16,3}$ & 5600 & 400 & 800 & 60 & 2000 & 4500 \\
\hline \multirow{3}{*}{$\mathrm{SSC}_{17}$} & $\mathrm{~S}_{17,1}$ & 5600 & 350 & 700 & 80 & 2500 & 4700 \\
\hline & $\mathrm{S}_{17,2}$ & 4000 & 350 & 440 & 70 & 2500 & 4500 \\
\hline & $\mathrm{S}_{17,3}$ & 5000 & 400 & 500 & 70 & 1500 & 4500 \\
\hline \multirow{3}{*}{$\mathrm{SSC}_{18}$} & $\mathrm{~S}_{18,1}$ & 6300 & 350 & 700 & 80 & 1800 & 5500 \\
\hline & $S_{18,2}$ & 4000 & 350 & 900 & 70 & 2000 & 4700 \\
\hline & $\mathrm{S}_{18,3}$ & 3500 & 600 & 700 & 60 & 1800 & 5500 \\
\hline \multirow{3}{*}{$\mathrm{SSC}_{19}$} & $S_{19,1}$ & 6300 & 500 & 440 & 70 & 1800 & 4700 \\
\hline & $\mathrm{S}_{19,2}$ & 4000 & 350 & 800 & 60 & 2500 & 4700 \\
\hline & $\mathrm{S}_{19,3}$ & 5200 & 400 & 415 & 85 & 1500 & 5000 \\
\hline
\end{tabular}

\section{References}

1. Ansari, Z.N.; Kant, R. A state-of-art literature review reflecting 15 years of focus on sustainable supply chain management. J. Clean. Prod. 2017, 142, 2524-2543. [CrossRef]

2. Shekarian, S.; Amin, S.H.; Shah, B.; Tosarkani, B.M. Design and optimisation of a soybean supply chain network under uncertainty. Int. J. Bus. Perform. Supp. Ch. M 2020, 11, 176-200. [CrossRef]

3. Khan, S.A.R.; Zhang, Y.; Kumar, A.; Zavadskas, E.; Streimikiene, D. Measuring the impact of renewable energy, public health expenditure, logistics, and environmental performance on sustainable economic growth. Sustain. Dev. 2020, 28, 833-843. [CrossRef]

4. Elfarouk, O.; Wong, K.Y.; Wong, W.P. Multi-objective optimization for multi-echelon, multi-product, stochastic sustainable closed-loop supply chain. J. Ind. Prod. Eng. 2021, 1-19. [CrossRef]

5. Goudarzi, Z.; Seifbarghy, M.; Pishva, D. Bi-objective modeling of a closed-loop multistage supply chain considering the joint assembly center and reliability of the whole chain. J. Ind. Prod. Eng. 2021, 1-23. [CrossRef]

6. Tosarkani, B.M.; Amin, S.H. A multi-objective model to configure an electronic reverse logistics network and third party selection. J. Clean. Prod. 2018, 198, 662-682. [CrossRef]

7. Khan, S.A.R.; Yu, Z.; Golpira, H.; Sharif, A.; Mardani, A. A state-of-the-art review and meta-analysis on sustainable supply chain management: Future research directions. J. Clean. Prod. 2021, 278, 123357. [CrossRef]

8. Khodakarami, M.; Shabani, A.; Saen, R.F.; Azadi, M. Developing distinctive two-stage data envelopment analysis models: An application in evaluating the sustainability of supply chain management. Measurement 2015, 70, 62-74. [CrossRef]

9. Yousefi, S.; Mahmoudzadeh, H.; Jahangoshai Rezaee, M. Using supply chain visibility and cost for supplier selection: A mathematical model. Int. J. Manag. Sci. Eng. Manag. 2017, 12, 196-205. [CrossRef]

10. Raut, R.D.; Mangla, S.K.; Narwane, V.S.; Gardas, B.B.; Priyadarshinee, P.; Narkhede, B.E. Linking big data analytics and operational sustainability practices for sustainable business management. J. Clean. Prod. 2019, 224, 10-24. [CrossRef]

11. Seuring, S.; Müller, M. From a literature review to a conceptual framework for sustainable supply chain management. J. Clean. Prod. 2008, 16, 1699-1710. [CrossRef] 
12. Khan, S.A.R.; Zhang, Y.; Golpîra, H.; Dong, Q. The impact of green supply chain practices in business performance: Evidence from Pakistani FMCG firms. J. Adv. Manuf. Syst. 2018, 17, 267-275. [CrossRef]

13. Rohmer, S.U.K.; Gerdessen, J.C.; Claassen, G.D.H. Sustainable supply chain design in the food system with dietary considerations: A multi-objective analysis. Eur. J. Oper. Res. 2019, 273, 1149-1164. [CrossRef]

14. Tosarkani, B.M.; Amin, S.H.; Zolfagharinia, H. A scenario-based robust possibilistic model for a multi-objective electronic reverse logistics network. Int. J. Prod. Econ. 2020, 224, 107557. [CrossRef]

15. Zhao, T.; Xie, J.; Chen, Y.; Liang, L. Coordination efficiency in two-stage network DEA: Application to a supplier-manufacturer sustainable supply chain. Int. J. Logist. Res. App. 2021, 1-22. [CrossRef]

16. Rezaee, M.J.; Yousefi, S.; Hayati, J. A multi-objective model for closed-loop supply chain optimization and efficient supplier selection in a competitive environment considering quantity discount policy. J. Ind. Eng. Int. 2017, 13, 199-213. [CrossRef]

17. Yousefi, S.; Jahangoshai Rezaee, M.; Solimanpur, M. Supplier selection and order allocation using two-stage hybrid supply chain model and game-based order price. Oper. Res. 2021, 21, 553-588. [CrossRef]

18. Borgheipour, H.; Lotfi, F.H.; Moghaddas, Z. Implementing energy efficiency for target setting in the sugar industry of Iran. Int. J. Environ. Sci. Technol. 2017, 14, 1697-1712. [CrossRef]

19. Rezaee, M.J.; Yousefi, S.; Baghery, M.; Chakrabortty, R.K. An intelligent strategy map to evaluate improvement projects of auto industry using fuzzy cognitive map and fuzzy slack-based efficiency model. Comput. Ind. Eng. 2021, 151, 106920. [CrossRef]

20. Yu, M.C.; Su, M.H. Using fuzzy DEA for green suppliers selection considering carbon footprints. Sustainability 2017,9 , 495. [CrossRef]

21. He, X.; Zhang, J. Supplier selection study under the respective of low-carbon supply chain: A hybrid evaluation model based on FA-DEA-AHP. Sustainability 2018, 10, 564. [CrossRef]

22. Su, Y.; Sun, W. Sustainability evaluation of the supply chain with undesired outputs and dual-role factors based on double frontier network DEA. Soft Comput. 2018, 22, 5525-5533. [CrossRef]

23. Badiezadeh, T.; Saen, R.F.; Samavati, T. Assessing sustainability of supply chains by double frontier network DEA: A big data approach. Comput. Oper. Res. 2018, 98, 284-290. [CrossRef]

24. Zarbakhshnia, N.; Jaghdani, T.J. Sustainable supplier evaluation and selection with a novel two-stage DEA model in the presence of uncontrollable inputs and undesirable outputs: A plastic case study. Int. J. Adv. Manuf. Technol. 2018, 97, 2933-2945. [CrossRef]

25. Izadikhah, M.; Saen, R.F. Assessing sustainability of supply chains by chance-constrained two-stage DEA model in the presence of undesirable factors. Comput. Oper. Res. 2018, 100, 343-367. [CrossRef]

26. Kalantary, M.; Saen, R.F. Assessing sustainability of supply chains: An inverse network dynamic DEA model. Comput. Ind. Eng. 2019, 135, 1224-1238. [CrossRef]

27. Zhou, X.; Wang, Y.; Chai, J.; Wang, L.; Wang, S.; Lev, B. Sustainable supply chain evaluation: A dynamic double frontier network DEA model with interval type-2 fuzzy data. Inf. Sci. 2019, 504, 394-421. [CrossRef]

28. Krmac, E.; Djordjević, B. A new DEA model for evaluation of supply chains: A case of selection and evaluation of environmental efficiency of suppliers. Symmetry 2019, 11, 565. [CrossRef]

29. Lin, Y.; Yan, L.; Wang, Y.M. Performance evaluation and investment analysis for container port sustainable development in china: An inverse DEA approach. Sustainability 2019, 11, 4617. [CrossRef]

30. Tavassoli, M.; Saen, R.F.; Zanjirani, D.M. Assessing sustainability of suppliers: A novel stochastic-fuzzy DEA model. Sustain. Prod. Consum. 2020, 21, 78-91. [CrossRef]

31. Pachar, N.; Darbari, J.D.; Govindan, K.; Jha, P.C. Sustainable performance measurement of Indian retail chain using two-stage network DEA. Ann. Oper. Res. 2021, 1-39. [CrossRef]

32. Dobos, I.; Vörösmarty, G. Green supplier selection using a common weights analysis of DEA and EOQ types of order allocation. Manag. Decis. Econ. 2021, 42, 612-621. [CrossRef]

33. Vaez-Ghasemi, M.; Moghaddas, Z.; Saen, R.F. Cost efficiency evaluation in sustainable supply chains with marginal surcharge values for harmful environmental factors: A case study in a food industry. Oper. Res. 2021, 1-16. [CrossRef]

34. Shadab, M.; Saati, S.; Saen, R.F.; Khoveyni, M.; Mostafaee, A. Measuring congestion in sustainable supply chain based on data envelopment analysis. Neural Comput. Appl. 2021, 33, 12477-12491. [CrossRef]

35. Rajak, S.; Parthiban, P.; Dhanalakshmi, R. A DEA model for evaluation of efficiency and effectiveness of sustainable transportation systems: A supply chain perspective. Int. J. Logist. Syst. Manag. 2021, 40, 220-241. [CrossRef]

36. Tavassoli, M.; Fathi, A.; Saen, R.F. Assessing the sustainable supply chains of tomato paste by fuzzy double frontier network DEA model. Ann Oper. Res. 2021, 1-33. [CrossRef]

37. Jomthanachai, S.; Wong, W.P.; Lim, C.P. A Coherent Data Envelopment Analysis to Evaluate the Efficiency of Sustainable Supply Chains. IEEE Trans. Eng. Manag. 2021. [CrossRef]

38. Moghaddas, Z.; Vaez-Ghasemi, M.; Lotfi, F.H. A novel dea approach for evaluating sustainable supply chains with undesirable factors. Econ. Comput. Econ. Cyb. 2021, 55, 1-16. [CrossRef]

39. Fathi, A.; Saen, R.F. Assessing sustainability of supply chains by fuzzy Malmquist network data envelopment analysis: Incorporating double frontier and common set of weights. Appl. Soft Comput. 2021, 113, 107923. [CrossRef]

40. Song, J.; Ma, X.; Chen, R. A Profit Distribution Model of Reverse Logistics Based on Fuzzy DEA Efficiency-Modified Shapley Value. Sustainability 2021, 13, 7354. [CrossRef] 